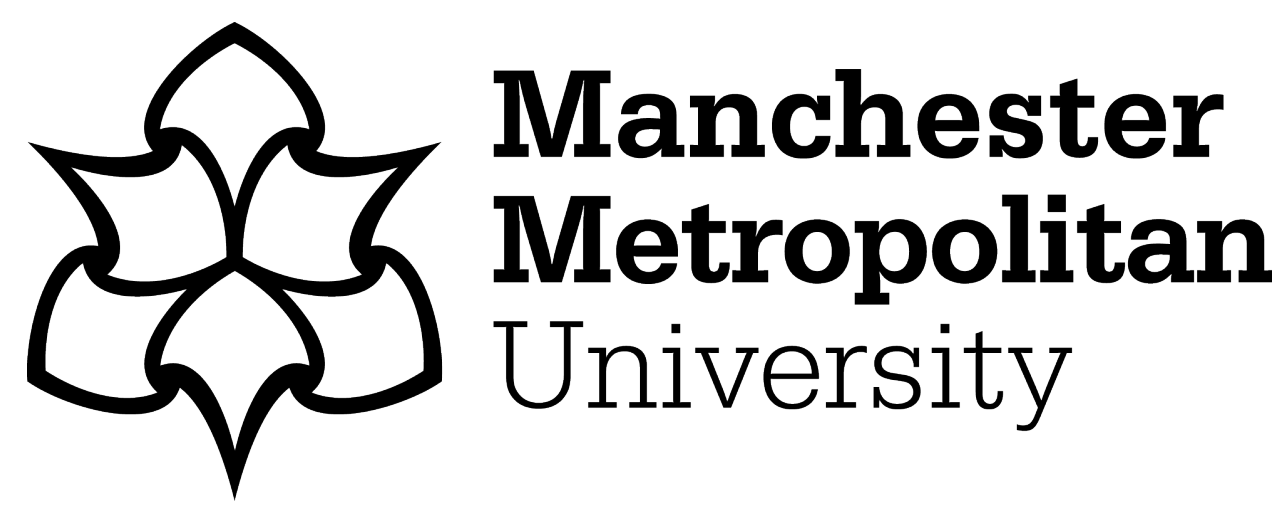

Xue, MA, Chen, Y, Zheng, J, Qian, L ORCID logoORCID: https://orcid.org/0000-0002-9716-2342 and Yuan, X (2019) Fluid dynamics analysis of sloshing pressure distribution in storage vessels of different shapes. Ocean Engineering, 192. p. 106582. ISSN 0029-8018

Downloaded from: https://e-space.mmu.ac.uk/624269/

Version: Accepted Version

Publisher: Elsevier

DOI: https://doi.org/10.1016/j.oceaneng.2019.106582

Please cite the published version 


\title{
Fluid dynamics analysis of sloshing pressure distribution in storage vessels of different shapes
}

\author{
Mi-An Xue ${ }^{1,2 *}$, Yichao Chen ${ }^{1,2}$, Jinhai Zheng ${ }^{1,2}$, Ling Qian ${ }^{1,2,3}$, Xiaoli Yuan ${ }^{4}$
}

${ }^{1}$ Key Laboratory of Coastal Disaster and Defence of Ministry of Education, Hohai University, Nanjing 210024, China

${ }^{2}$ College of Harbour Coastal and Offshore Engineering, Hohai University, Nanjing 210024, China

${ }^{3}$ Centre for Mathematical Modelling and Flow Analysis, Department of Computing and Mathematics, Manchester Metropolitan University, Manchester M1 5GD, United Kingdom

${ }^{4}$ College of Science, Hohai University, Nanjing 210024, China

\begin{abstract}
A series of numerical simulations were performed to investigate the influences of storage vessels shapes on sloshing dynamics under horizontal excitation by employing the open source code OpenFOAM, which has been extensively validated by experimental data for the sloshing flow problem. The results show that the membrane liquefied natural gas (LNG) tanks are subject to lower impact pressure than the cylindrical, rectangular and spherical tanks with the same volume of liquid and the overall tank dimensions, as the slope at the storage vessels bottom changes the flow direction of the liquid and therefore reduces the impact on the vertical wall. In the cylindrical and spherical tanks, higher impact pressure was found on the wall directly opposite to the excitation direction and the maximum impact point will shift away from the external excitation direction as the wave breaks up violently until a quasi-steady state of the sloshing wave rotating along the side wall is reached. The curved surface of the spherical tank could also help reduce the impact pressure when compared with the cylindrical tank.
\end{abstract}

Keywords: sloshing; storage vessels shape; pressure distribution; fluid dynamics analysis; OpenFOAM

\section{Introduction}

The liquid in the partially filled container will move back and forth, sometimes

\footnotetext{
*Corresponding author. mi-anxue@163.com
} 
violently, as the container undergoes accelerated motions, which is termed sloshing. The phenomenon of sloshing exists in various engineering problems and violent sloshing can cause large impact pressure and overall overturning moment, which will in turn have an adverse impact on the performance and integrity of equipment. Therefore, many researches have been devoted to the study of liquid sloshing dynamics in storage vessels of different shapes.

There are many factors that influence the intensity of sloshing, such as the type and depth of liquid, and the mode and amplitude of external excitations. In addition, the shape of liquid storage vessels can also have significant effects on the sloshing. In the previous studies, most of the work has been focused on the two-dimensional rectangular tank. Faltinsen (1974) and Faltinsen et al. (2000) and Faltinsen and Timokha (2001) developed a third-order steady-state solution of 2D rectangular vessel sloshing and established nonlinear analytical solutions of fluid sloshing in rectangular vessels by using a multimodal approach. Akyildiz and Ünal (2005) studied the pressure distributions at different locations on the tank wall and 3D effects on liquid sloshing through a programme of high quality experiments. Virella et al. (2008) analyzed the pressure distribution on the tank walls under various sloshing flow conditions using linear and nonlinear wave theory models. Liu and Lin (2008) developed a numerical model NEWTANK (New numerical Wave TANK) to investigate the three-dimensional non-linear liquid sloshing with broken free surfaces. Xue and Lin (2011) investigated the effects of ring baffle on reducing violent liquid sloshing by using their 3D turbulent free surface flow model and discussed the damping mechanism of the ring baffle. Xue et al. (2012; 2013 and 2017a) developed a finite difference model for solving the Navier-Stokes (NS) equations in conjunction with a turbulence model to investigate the viscous liquid sloshing-wave interaction with baffles in a tank. Xue et al. (2017b) conducted an experimental study on the effects of four types of vertical baffles on reducing sloshing intensity.

Most LNG carriers adopt the design of the membrane-type LNG cargo tank, so it is essential to investigate sloshing in this type of tanks for an improved design of their structures and operation safety. Abramson et al. (1976) studied liquid response characteristics under different tank geometries and fill levels both theoretically and experimentally. Lee et al. (2007a) studied the coupling and interactions between ship motion and inner-tank sloshing using a time-domain method. Lee et al. (2007b) conducted a series of parametric sensitivity studies on the LNG tank sloshing and 
concluded that the effects of viscosity and density ratio of the two fluids used e.g. water/air and oil/air are insignificant, while the compressibility of ullage space (air) plays an appreciable role. Graczyk and Moan (2008) analyzed a large sample of sloshing pressure measurements with a focus on the magnitude of individual sloshing impact events, and the associated temporal and spatial patterns. Ye et al. (2012) investigated ultimate capacity of the containment systems of large LNG carriers using nonlinear finite element method with failure modes under different boundary conditions analyzed in details. Zhao and Chen (2015) used a new coupled Level-Set and Volume-of-Fluid (CLSVOF) method based on the Finite-Analytic Navier-Stokes (FANS) approach for the study of the 3D sloshing flow in partially filled LNG tanks. Luo et al. $(2016 ; 2017)$ studied the three-dimensional sloshing in a scaled membranetype LNG tank numerically and experimentally. Investigated were the wave patterns, i.e. length-dominant, breadth-dominant, diagonal and swirling waves, and their relations with the excitation frequencies, which had been examined for rectangular tanks, but seldom for octagonal prismatic tanks. Zhao et al. (2018a) investigated sloshing properties in partially filled rectangular and membrane tank under translational and rotational excitations.

Despite of the work mentioned above, much less attention has been paid to liquid sloshing within the cylindrical tanks, which are also widely used, such as for oil storage on land or offshore platforms and at nuclear power plants. Chiba and Abe (1999) investigated the non-linear hydro-elastic vibration of a cylindrical tank with an elastic bottom. Maleki and Ziyaeifar (2008) investigated the potential of baffles in increasing the hydrodynamic damping on sloshing in circular-cylindrical tanks. Chen et al. (2007) applied a boundary element method to study the sloshing behaviors of cylindrical and rectangular liquid tanks subjected to harmonic and seismic excitations. Dragomir et al. (2012) discussed the energy dissipation characteristics of granular materials sloshing in a rotating cylindrical container. Akyildiz et al. (2013) carried out a series of experiments to study the liquid sloshing in a cylindrical tank with various filling levels and ring baffles under the excitations of roll motion. Rawat et al. (2019) using Finite Element Method (FEM) to study cylindrical and rectangular rigid liquid storage tanks subjected to seismic base excitation.

The sloshing effects in the spherical tanks are also of major concern (Zhao et al., 2018b), which have significant industrial applications in refineries, power plants, LNG tankers and fuel tank in satellites. Wang and Deng (1985) investigate the 
sloshing in spherical tanks under low-gravity conditions. Mciver (1989) used the linear theory to calculate the frequencies of free oscillations in spherical tanks. Karamanos (2006) developed a mathematical model for investigating the sloshing effects on the dynamic response of spherical liquid containers under earthquake excitation. Van Twillert (2015) describes linear potential and radiation potential theory to analyze the effect of sloshing on ship motions.

As discussed above, a great deal of efforts has been devoted to study the liquid sloshing problem, but most work so far has been focused on sloshing in a particular shape of storage vessels, and there were few researches which considered the differences in sloshing wave kinematics and dynamics due to different storage vessel shapes, especially under the condition of the same volume of liquid. Therefore, this work aims to contribute to this issue by conducting a systematic numerical investigation of liquid sloshing within several storage vessels of different shapes using OpenFOAM, and discuss their effects on sloshing dynamics and especially for the pressure distribution.

\section{Numerical Model}

The study employs the InterDyMFoam module in the OpenFOAM, which is a two-phase Navier-Stokes (NS) solver for incompressible, isothermal immiscible fluids with optional mesh motion and mesh topology changes including adaptive re-meshing. The volume of fluid (VOF) approach based on the phase-fraction is used to capture the interface in this model. The continuity equation, momentum equation and phase equation are, respectively, as follows.

$$
\begin{aligned}
& \frac{\partial \rho}{\partial t}+\nabla \cdot(\rho \boldsymbol{U})=0 \\
& \frac{\partial \rho \boldsymbol{U}}{\partial t}+\nabla \cdot(\rho \boldsymbol{U} \boldsymbol{U})-\nabla \cdot \boldsymbol{\tau}=C \kappa \nabla \alpha-g \boldsymbol{h} \nabla \rho-\nabla p_{r g h} \\
& \frac{D \alpha}{D t}=\frac{\partial \alpha}{\partial t}+\nabla \cdot(\alpha \boldsymbol{U})=0
\end{aligned}
$$

where $\rho$ is the density, $\boldsymbol{U}$ is the fluid velocity vector, $\boldsymbol{\tau}$ is the shear stress, $C$ is the surface tension coefficient, $\kappa$ is the interface curvature, $\alpha$ is the volume fraction, $g$ is the acceleration of gravity, $\boldsymbol{h}$ is the position vector of the mesh center measured from the coordinate's origin and $p_{r g h}$ is the dynamic pressure. Two fluids e.g. water and air are solved using the single fluid approach, whose density $\rho$ and the viscosity 
coefficient $\mu$ are calculated respectively by the densities $\left(\rho_{1}, \rho_{2}\right)$ and viscosities $\left(\mu_{1}, \mu_{2}\right)$ of the underlying fluids and volume fraction $\alpha$

$$
\begin{aligned}
& \rho=\alpha \rho_{1}+(1-\alpha) \times \rho_{2} \\
& \mu=\alpha \mu_{1}+(1-\alpha) \times \mu_{2}
\end{aligned}
$$

OpenFOAM uses the Finite Volume Method to discretize its governing equations. In this work, a first-order implicit Euler discretization scheme is used for approximating the time derivative terms, e.g. $\partial \boldsymbol{U} / \partial \mathrm{t}$ and $\partial \alpha / \partial \mathrm{t}$. The Gauss linear discretization scheme is selected for dealing with the gradient estimation, e.g. $\nabla \boldsymbol{U}$. Gauss linear corrected is used for the Laplacian derivative terms, like $\nabla \mathrm{p}_{\mathrm{rgh}}, \nabla \rho$ and $\nabla \mu$. Regarding the divergence terms such as $\nabla \cdot(\boldsymbol{U} \boldsymbol{U})$ and $\nabla \cdot(\boldsymbol{U} \alpha)$, the vanLeer scheme is applied. The PIMPLE algorithm, which is a combination of PISO (Pressure Implicit with Splitting of Operator) and SIMPLE (Semi-Implicit Method for Pressure-Linked Equations), is used for the velocity-pressure coupling. As presented in the reference (Luo et al., 2016), the turbulence was not considered in calculation of violent sloshing without baffle. Good agreement between the numerical and experimental results was still obtained. The laminar model is thus used in the numerical calculation due to the above-mentioned reason and the advantage of requiring considerably less CPU time. More details of the InterDyMFoam solver can be found in the OpenFOAM website or other references (e.g. in https://openfoam.org/).

\section{Model validation}

In this section, the numerical model is validated against available experimental data. The first case is to show the accuracy of the simulation of sloshing in a rectangular tank, and the next two cases are given for the validation of sloshing in a membrane-type LNG tank. In order to demonstrate the capability and accuracy of the flow solver in capturing violent sloshing in three-dimensional cylindrical tanks, two further test cases have been selected for the validation of sloshing in these types of storage vessels through a detailed analysis and comparison of pressure distribution and the free surface profiles.

\subsection{Rectangular tank}

The two-dimensional sloshing experiment carried out by Liu and Lin (2008) was used here. The tank has a size of $L=0.57 \mathrm{~m}$ (length) and $H=0.3 \mathrm{~m}$ (height) with a still water level of $h=0.15 \mathrm{~m}$. The tank follows a sinusoidal translational motion $x=-a \sin \omega t$ with the amplitude $a=0.005 \mathrm{~m}$ and the frequency $\omega=6.0578 \mathrm{rad} / \mathrm{s}$. 
Based on the mesh refinement test done in the earlier work (Chen and Xue, 2018), a uniform mesh with a cell size of $0.005 \mathrm{~m}$ by $0.005 \mathrm{~m}$ was adopted for this test case. The installation position of the wave gauge is $20 \mathrm{~cm}$ from the right tank wall according to the experiments conducted by Liu and Lin (2008). Fig. 1 shows that the present numerical results for the wave elevation at the selected location are in very good agreement with the experimental data.

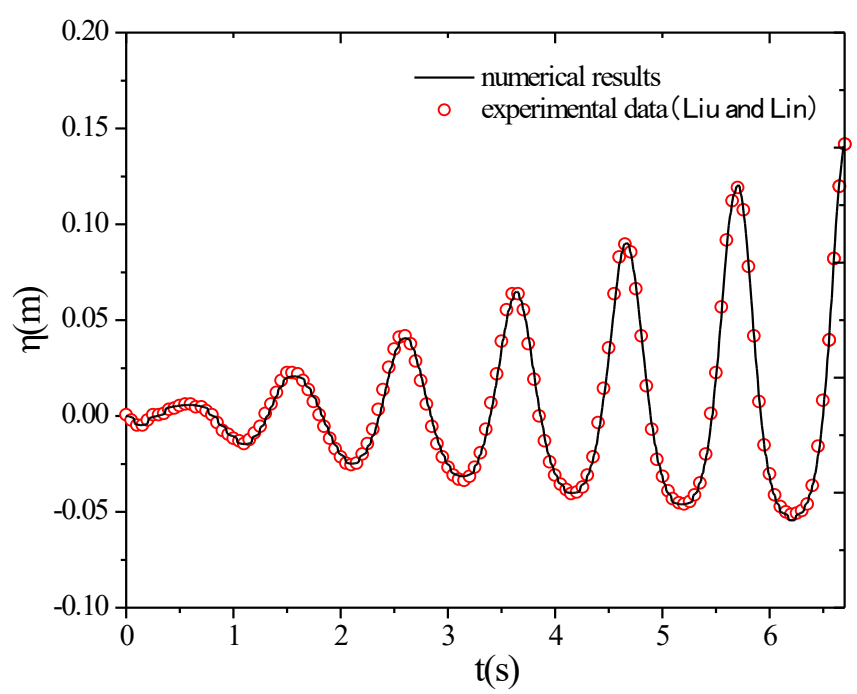

Fig. 1. Comparison of the time history of free surface elevation between the experimental data (Liu and Lin, 2008) and numerical results.

\section{2. $L N G$ tank}

The experiment carried out by Arai (1984) was used for validating the simulation of liquid sloshing in the LNG tank. The inner dimensions of the tank and the layout of pressure sensors are shown in Fig. 2. The tank undergoes a sinusoidal motion $x=a \sin \omega t$, whose amplitude is $a=0.005 \mathrm{~m}$ and frequency $\omega=6.28 \mathrm{rad} / \mathrm{s}$ (close to the fundamental frequency of the sloshing system estimated by the linear wave theory). According to the comparison of the pressure at P1 (Fig. 2), the match between the present numerical results and the experimental data is good. 

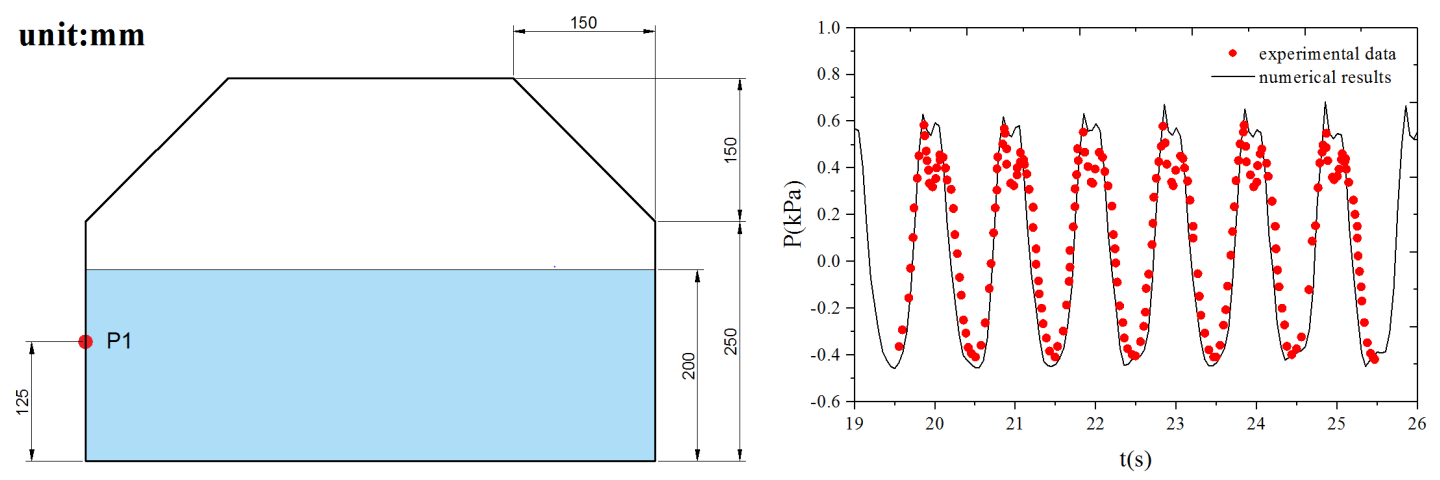

Fig. 2. The tank geometry and the layout of the pressure sensor and the comparison of the time history of pressure at P1 between the experimental data from Arai (1984) and the present numerical results (right).

The second validation case used the experiments conducted by Koh et al. (2013) and Luo et al. (2016). The dimensions of the tank and the position of the pressure probe are as shown Fig. 3, the experiments are conducted on a shake table, which generate translational motion governed by $A(t) \sin \omega t$, To avoid a sudden jerk on fluid caused by the non-zero initial velocity of the shake table, the excitation with a linear ramping function $A_{0} t / t_{r}$ is used, the ramping time $t_{r}=10 \mathrm{~s}$, and $A_{0}=0.005 \mathrm{~m}, \omega=6.618$ $\mathrm{rad} / \mathrm{s}$, the longitudinal axis of the tank is not in line with that of the shake table but with an oblique angle $45^{\circ}$. Fig. 3 shows the comparisons between the present numerical results and experimental data and it is clearly shown that the numerical model performs well in predicting the sloshing in LNG tank.
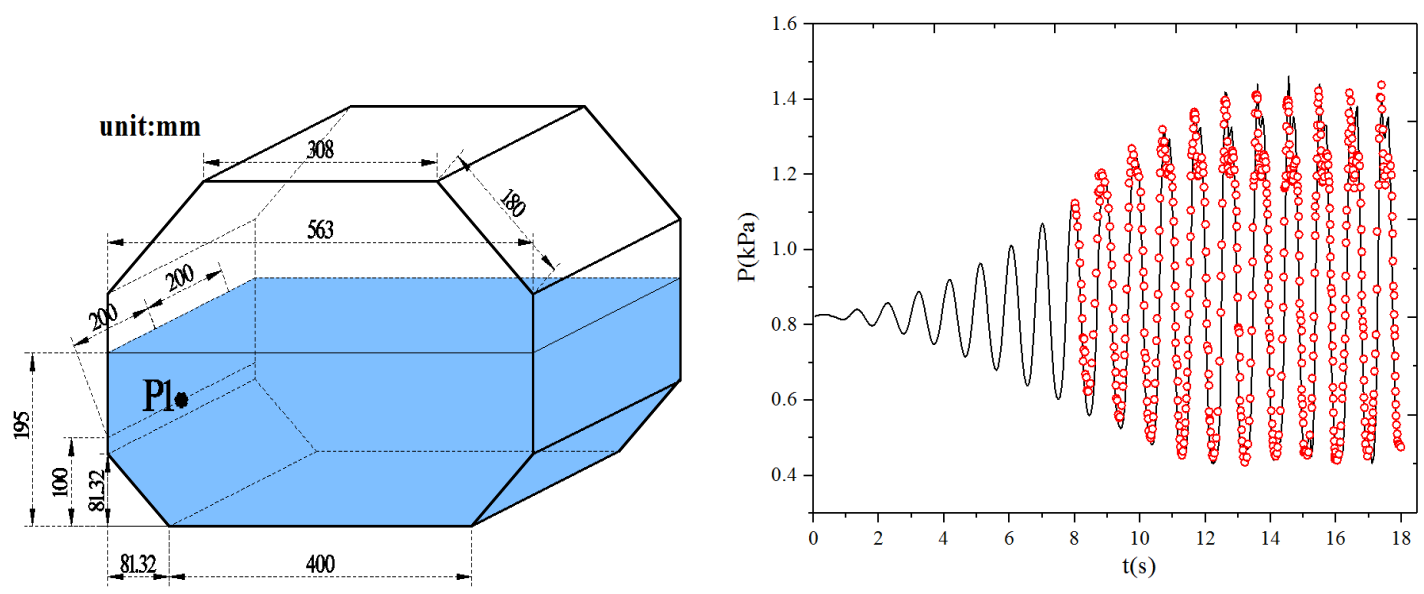

Fig. 3. The tank geometry and the layout of the pressure probe and the comparison of the time history of pressure at P1 between the experimental data from Luo (2016) and the present numerical results (right).

\subsection{Cylindrical tank}

Two more cases are studied to validate the accuracy of the model in predicting 
three-dimensional sloshing waves. The first one considered here is the sloshing experiment carried out by Akyildiz et al. (2013). The height and diameter of the cylindrical tank are $0.8 \mathrm{~m}$ and $0.695 \mathrm{~m}$ respectively (Fig. 4). The tank undergoes a sinusoidal rotation $\theta=\theta_{0} \sin \omega t$ around a transverse axis through the tank centre with the amplitude of $\theta_{0}=4^{\circ}$ and the frequency of $\omega=1.43 \mathrm{rad} / \mathrm{s}$, and the filling level is $25 \%$. The second experiment was performed by Chen et al. (2007), in which the cylindrical tank has a radius $R$ of $0.3 \mathrm{~m}$, and a water level $h$ of $0.1 \mathrm{~m}$ (Fig. 5). The harmonic ground displacement is given by $x=A \sin \omega t$, where the amplitude $A=0.0005$ $\mathrm{m}$ and the frequency $\omega=\omega_{1}=5.74 \mathrm{rad} / \mathrm{s}$. It can be clearly shown from Fig. 4 and 5 that the present numerical results of the pressure and the free surface elevation are in excellent agreement with the experimental data.
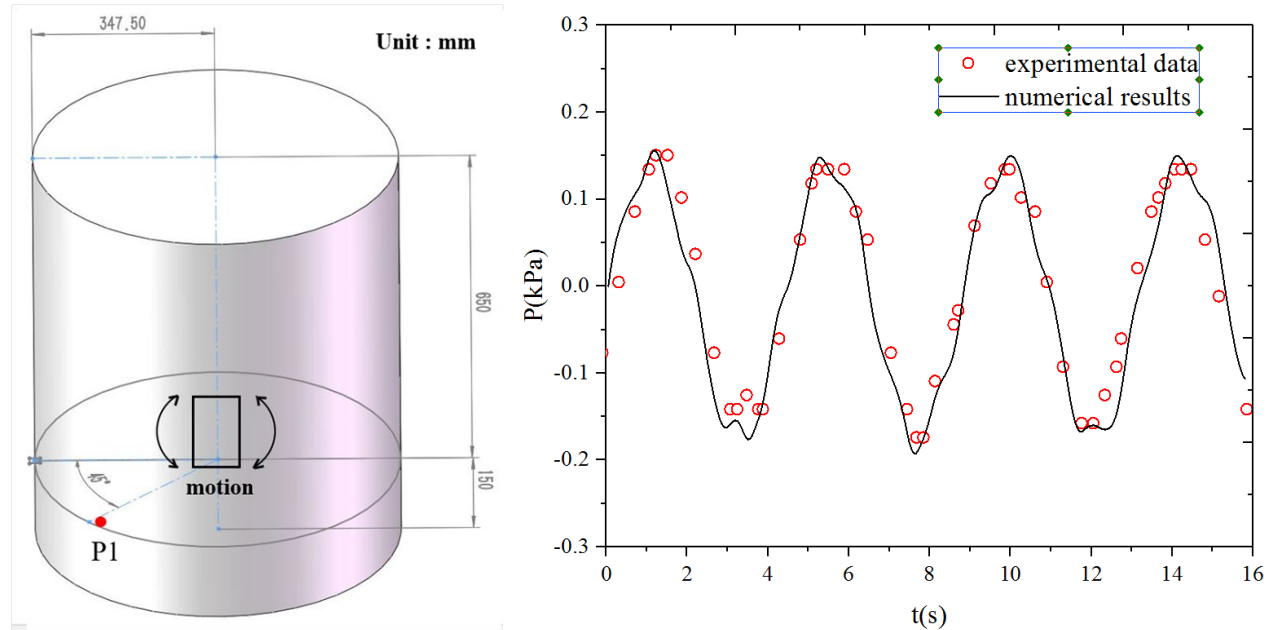

Fig. 4. The model parameters and the comparison of the time history of pressure at P1 between the experimental data from Akyildiz et al. (2013) and the present numerical results. 

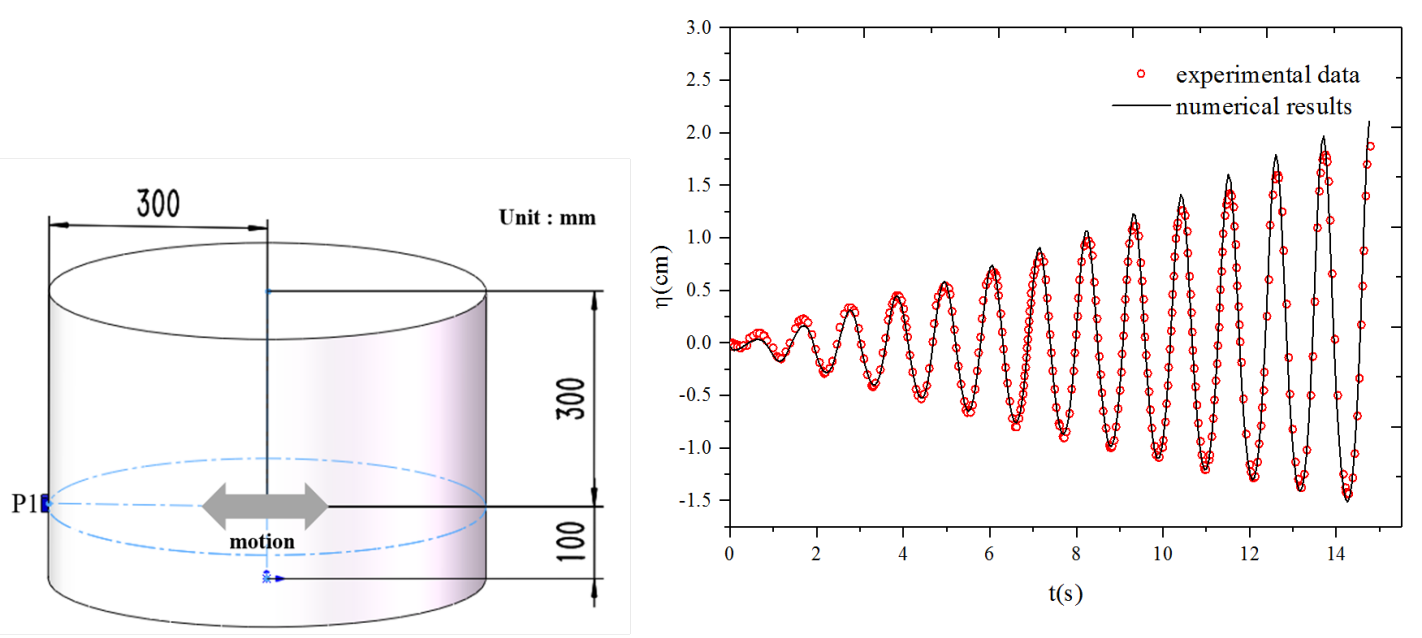

Fig. 5. The model parameters and the comparison of the time history of free surface elevation at P1 between the experimental data from Chen et al. (2007) and the present numerical results.

\subsection{Spherical tank}

In this section, the available experimental data was utilized for the validation of sloshing in a spherical tank. The experiments were carried out by Chiba et al. (2016). As shown in Fig. 6, the inner radius of the sphere is $0.1425 \mathrm{~m}$, and the filling ratio is $50 \%$. The vertical sinusoidal excitation $z=\frac{G g}{(2 \pi f)^{2}} \sin 2 \pi f t$ is applied to the spherical tank with $f=5.8 \mathrm{~Hz}$ and $G=0.06$, where $G$ is the ratio between the excitation acceleration and gravitational acceleration. The velocity of response wave measured at the flange of the test tank (P1) was compared in Fig. 6, which shows a good agreement between the experimental data and the present numerical results.
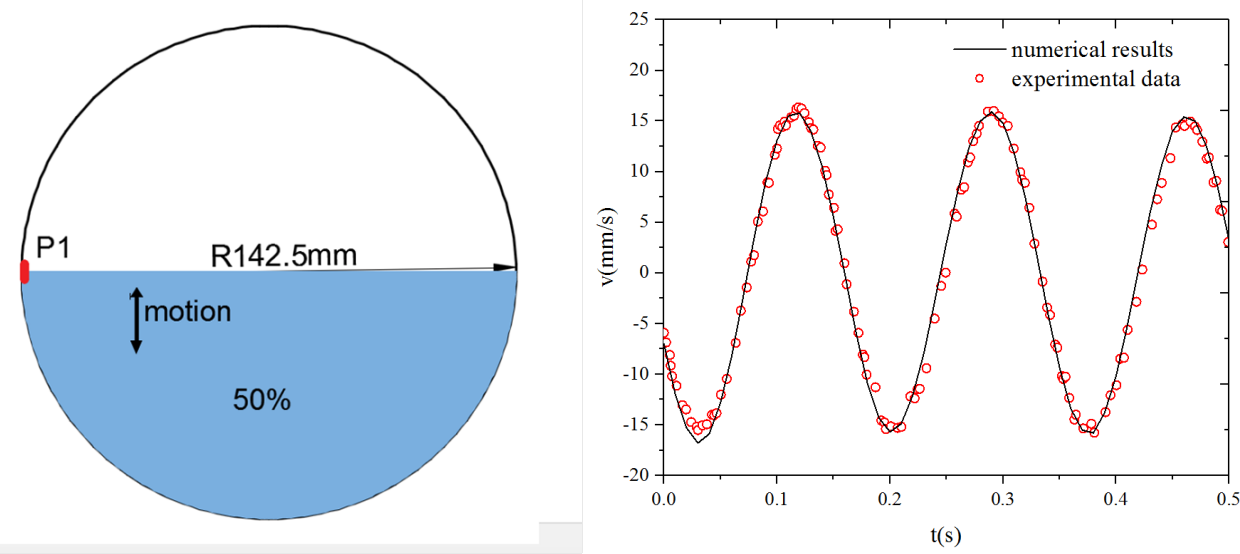

Fig. 6. The model parameters and the comparison of the time history of response 
wave velocity at P1 between the experimental data from Chiba et al. (2016) and the present numerical results.

\section{Liquid sloshing in storage vessels of different shapes}

\subsection{Numerical setup}

To investigate the potential difference in sloshing impact pressure due to different container shapes, the numerical simulations of liquid sloshing in rectangular, LNG, cylindrical and spherical tanks with the same volume of liquid have been carried out in this work. The configurations of liquid tanks along with the computational mesh used are shown in Fig. 7. For the cylindrical tank, a radius of $0.24 \mathrm{~m}$ and a height of $0.4 \mathrm{~m}$ are considered and for the LNG and the rectangular tanks, they have the same length $(0.48 \mathrm{~m})$ and height $(0.33 \mathrm{~m})$, but with a slightly different width of $0.317 \mathrm{~m}$ and $0.396 \mathrm{~m}$ respectively to keep the volume of the contained liquid the same. The spherical tank has a diameter of $0.396 \mathrm{~m}$ and a maximum liquid height of $0.198 \mathrm{~m}$. The movement of the tanks are subjected to sinusoidal excitation motion: $x=A \sin (\omega t)$. In the calculation, the time step size is automatically adjusted according to the specified Courant number, which is set at a value of less than 0.5 .

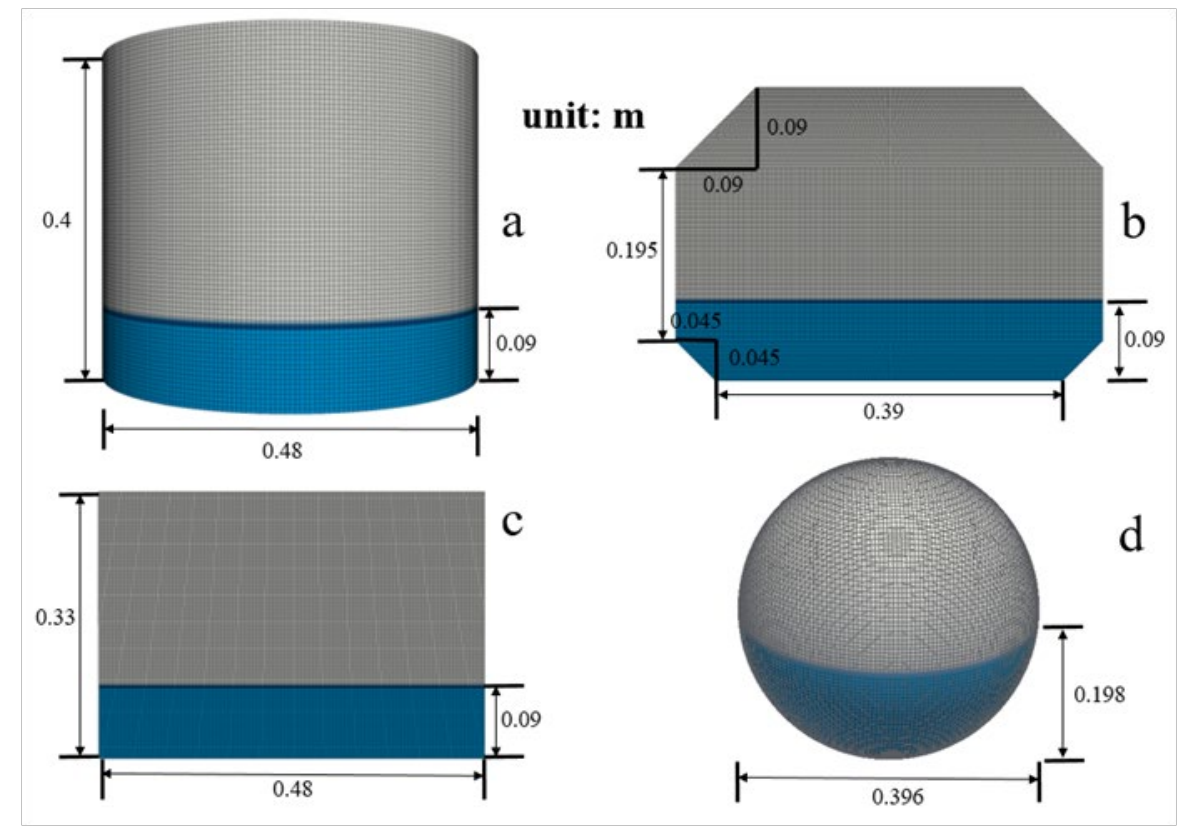

Fig. 7. Configurations of the tanks and computational mesh (a. cylindrical tank, b.

LNG tank, c. rectangular tank, d. spherical tank). 
With the assumption of potential flow theory, the first order natural frequencies of the rectangular tank and the LNG tank can be analytically determined as (Faltinsen and Timokha, 2009):

$$
\omega_{1}=\sqrt{g \frac{\pi}{L} \tanh \left(\frac{\pi}{L} h\right)}
$$

where $h$ is the water level, $L$ is the length of the tank. According to Equation (5), the natural frequency of the LNG tank and the rectangular tank is $5.83 \mathrm{rad} / \mathrm{s}$.

And the first order natural frequency of the cylindrical tank using linear wave theory is given by (Chen et al., 2007):

$$
\omega_{1}=\sqrt{\frac{\lambda_{l} g}{R} \tanh \left(\lambda_{1} \frac{h}{R}\right)}
$$

where $\lambda_{1}$ is coefficient of first derivative of the first order Bessel function $J_{1}{ }^{\prime}\left(\lambda_{1}\right)$, and the numerical value of $\lambda_{l}=1.8412$. According to Equation (6), the natural frequency of the cylindrical tank is $6.71 \mathrm{rad} / \mathrm{s}$.

The natural frequency of the spherical tank which can be obtained by the following formula (Wang and Deng, 1985) is $8.124 \mathrm{rad} / \mathrm{s}$ :

$$
\omega_{1}=\sqrt{\frac{4 \mathrm{~g}}{3 R}}
$$

Table 1 lists the natural frequencies of the four tanks and test frequencies that have been applied. As discussed in Zhang et al. (2018), nonlinear interactions can occur in shallow water sloshing. To observe the nonlinear sloshing phenomenon, in the numerical experiments, the water levels are set at $0.09 \mathrm{~m}$ and $0.198 \mathrm{~m}$ respectively, and two external excitation amplitudes of $0.001 \mathrm{~m}$ and $0.007 \mathrm{~m}$ are selected in this

\begin{tabular}{|c|c|c|c|c|c|c|}
\hline \multicolumn{5}{|c|}{ frequency $(\mathrm{rad} / \mathrm{s})$} & $\begin{array}{l}\text { amplitude( } \\
\mathrm{m})\end{array}$ & $\begin{array}{l}\text { water } \\
\text { level(m) }\end{array}$ \\
\hline$\omega / \omega_{1}$ & $\begin{array}{l}\text { cylindric } \\
\text { al tank }\end{array}$ & $\begin{array}{l}\text { LNG } \\
\text { tank }\end{array}$ & $\begin{array}{l}\text { rectangul } \\
\text { ar tank }\end{array}$ & $\begin{array}{l}\text { spherical } \\
\text { tank }\end{array}$ & \multirow{4}{*}{$\begin{array}{l}0.001 \\
0.007\end{array}$} & \multirow{4}{*}{$\begin{array}{l}0.09 \\
0.198\end{array}$} \\
\hline 0.7 & 4.697 & 4.081 & 4.081 & 5.687 & & \\
\hline 0.8 & 5.368 & 4.664 & 4.664 & 6.499 & & \\
\hline 0.9 & 6.039 & 5.247 & 5.247 & 7.312 & & \\
\hline
\end{tabular}
study.

Table 1. The numerical case parameters. 


\begin{tabular}{lllll|l|}
0.95 & 6.375 & 5.539 & 5.539 & 7.718 & \\
1 & 6.71 & 5.83 & 5.83 & 8.124 & \\
1.03 & 6.911 & 6.306 & 6.306 & 8.368 & \\
1.05 & 7.046 & 6.122 & 6.122 & 8.53 & \\
1.07 & 7.18 & 6.551 & 6.551 & 8.693 & \\
1.1 & 7.381 & 6.413 & 6.413 & 8.936 & \\
1.2 & 8.052 & 6.996 & 6.996 & 9.749 & \\
1.3 & 8.723 & 7.579 & 7.579 & 10.561 & \\
\hline
\end{tabular}

\subsection{Mesh Convergence Test}

Mesh convergence studies are performed to determine the suitable mesh sizes for the simulation of sloshing in four storage vessels of different shapes. The computational meshes used include the two-dimensional uniform mesh with parallelogram cells for the rectangular and LNG tanks and the three-dimensional mesh for the cylindrical and spherical tanks. Three mesh sizes are considered in each test case and their average length scales are $0.002 \mathrm{~m}, 0.005 \mathrm{~m}$ and $0.008 \mathrm{~m}$, respectively. It is worth noting that the external excitation of the cases is the sinusoidal motion $x=a \sin \omega t$ with amplitude $a=001 \mathrm{~m}$ and frequency $\omega=\omega_{1}$. The comparisons of the pressure data for each case with different mesh sizes are plotted in Fig. 8, from which it can be seen that although the results from the mesh size of $0.008 \mathrm{~m}$ differ from the other results, the results from the two finer meshes are almost identical. Thus, a mesh size of $0.005 \mathrm{~m}$ is employed in the following studies considering the time-saving. Meanwhile, the numerical results with a mesh size of $0.005 \mathrm{~m}$ are also considered to be the benchmark results of pressure of storage vessels of different shapes. 

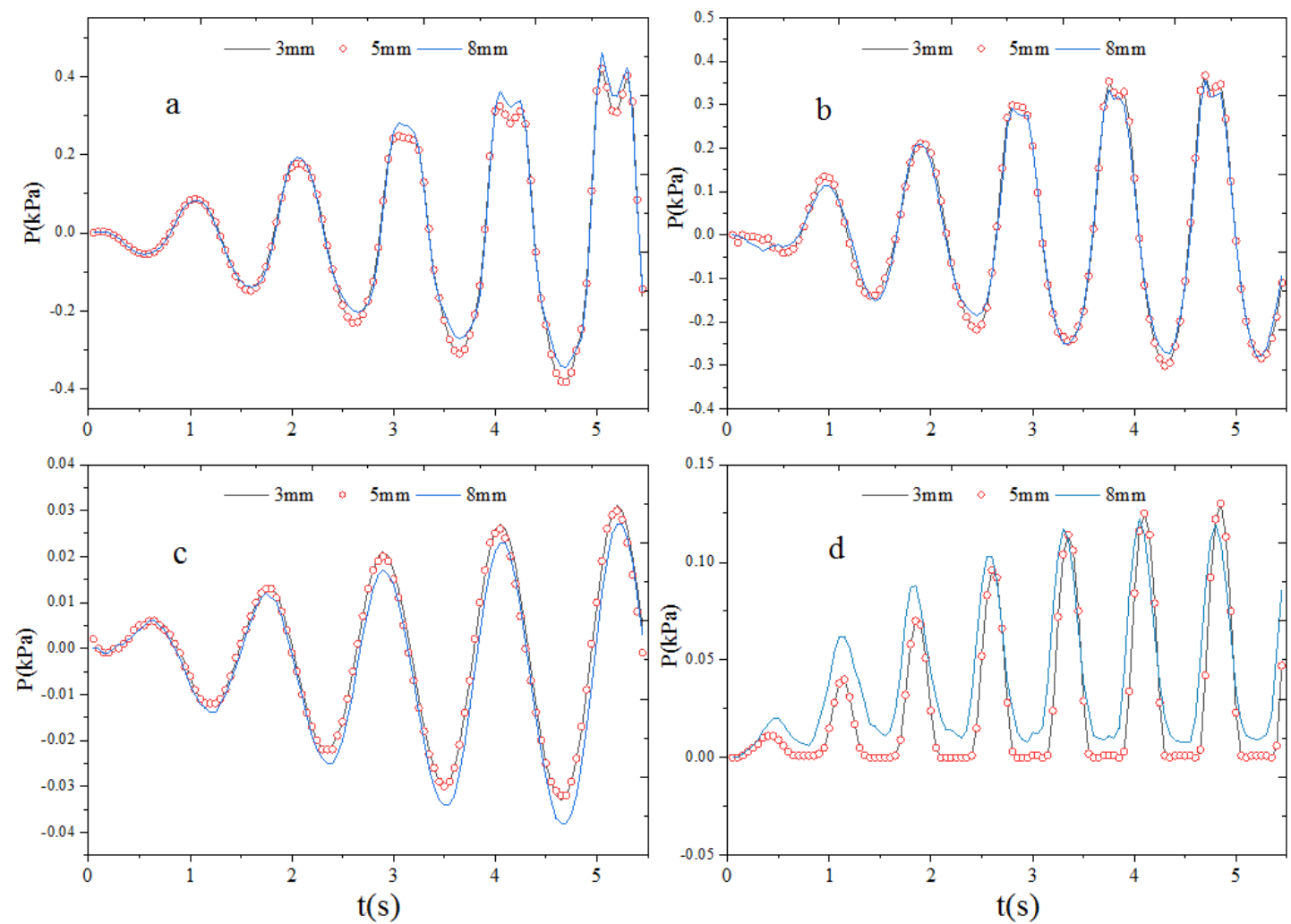

Fig. 8. The comparisons of the pressure data in the cases with different mesh sizes (a. rectangular tank, b. LNG tank, c. cylindrical tank, d. spherical tank).

\subsection{Results and discussion}

\subsubsection{Impact pressure in storage vessels of different shapes}

In this section, the validated numerical model is employed to study the small amplitude liquid sloshing in storage vessels of different shapes, with a focus on the impact pressure distribution. Fig. 9 shows the maximum impact pressure (only at the still water level where the most violent impact occurs possibly) -frequency response curves in the four storage vessels. Noted the pressure at the still water level is not necessarily the maximum along the walls of the storage vessel. It can be observed that whether at the resonate mode or not, largest impact pressures were found in the cylindrical tank, while the impact pressures in the LNG tank are significantly lower than the other three tanks, which means under the same volume of liquid, LNG tanks are subject to smaller impact pressure than cylindrical, rectangular and spherical tanks. The most severe liquid impact occurs when the tank is at resonant frequency, it should be noted that the maximum response frequency of the cylindrical tank is at the natural frequency $\omega_{1}$, but the maximum response frequency of the spherical tank is at the $1.07 \omega_{1}$, and for the other two tanks it happens at the frequency of $1.03 \omega_{1}$. According 
to our previous studies (Chen and Xue, 2018), the resonant hysteresis (namely the maximum response frequency higher than the natural frequency due to the nonlinearity) can be observed in certain sloshing tanks at low filling level. However, it was found that this phenomenon did not occur in the cylindrical tank but it is more profound in the spherical tank, as shown in Fig. 9.

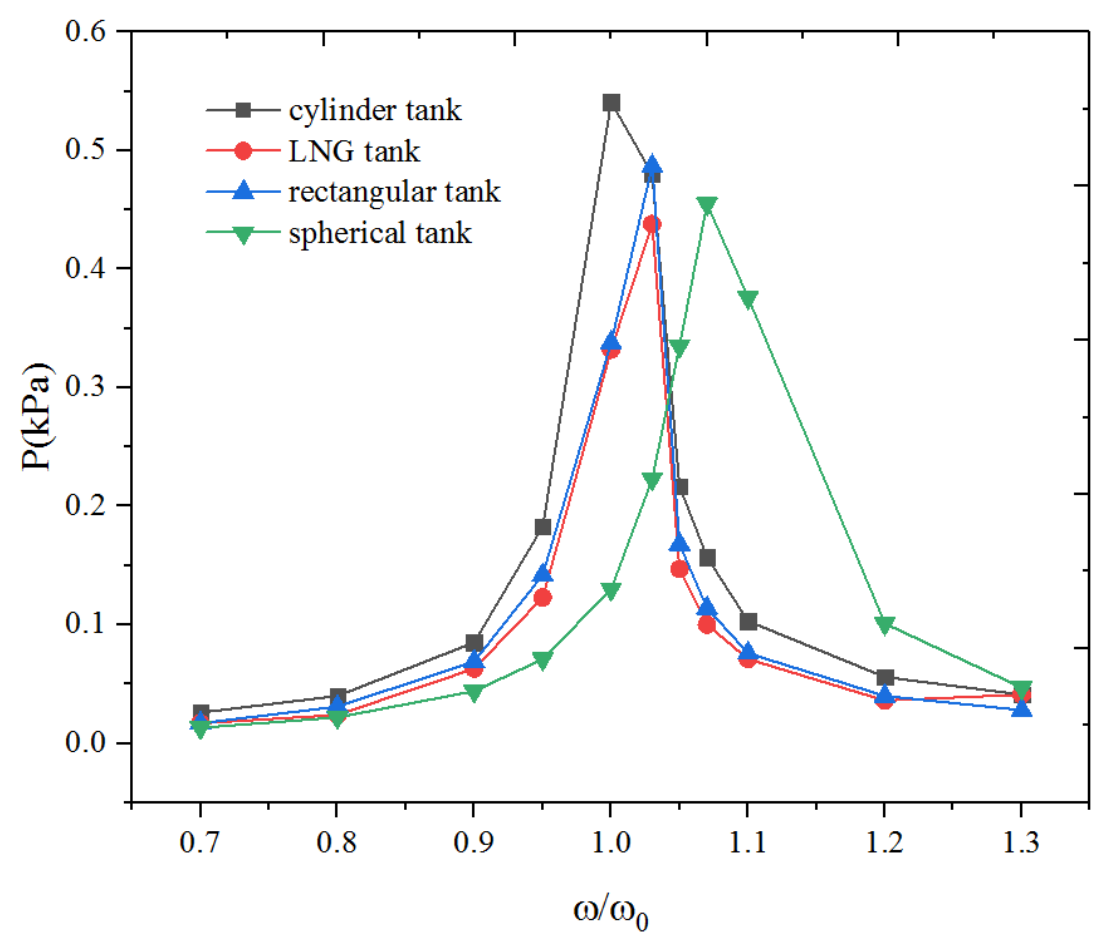

Fig. 9. Maximum impact pressure on the side wall of storage vessels of different shapes versus the external frequencies.

The predicted pressure distribution at the maximum response frequency in the four tanks is presented in Fig. 10. It is worth mentioning that the z-coordinate represents the vertical distance from the tank floor and the y-coordinate represents the impact pressure. It can be clearly seen that the impact pressure first increases with the height, then reaches its peak value before decreases. The changes in the maximum impact pressures on the side wall below the still water level are relatively small for the tanks with a vertical side wall. For example, for the cylindrical tank, the relative change between the impact pressures at the tank bottom and the still water level is $19.6 \%$ in, and for the LNG and rectangular tanks, the differences are at $17.4 \%$ and 9.9\% respectively. However, for the spherical tank, the impact pressure at the still water level is about three times that of the bottom, which has certain implications for the tank design. In all the cases, as the free surface elevation due to small amplitude 
liquid sloshing is not large and the impact pressure above the still water level drops quickly.

Fig. 11 provides a time-continuous view of the computed impact pressure distribution along the center line of the side walls for a duration of 30 seconds at the maximum response frequency. The large impact pressure illustrated by the red area is local in both space and time. Concerning the size of the large impact area, it can be seen that the largest is for the cylindrical tank, followed by the rectangular tank and the spherical tank, while the smallest is for the LNG tank. These results are consistent with those in Fig. 9. Concerning the impact time of the large pressure (i.e., the width of the red area), for the last three cases, the tank surfaces at the still water level were impacted for a longer time, while the surfaces above the still water level will be impacted for much shorter time due to the limited liquid climbing up. For the cylindrical tank, the positions at and below the still water level were all subjected to longer and larger impact pressure. Noted that the large impact area in the spherical tank is concentrated near the free surface, as shown in Fig. 11d, and its distribution is quite uniform across the vertical sidewalls for the other three tanks, as shown in Fig. 11a, Fig. 11b and Fig. 11c.

The FFT (Fast Fourier Transformation) of the pressure on the tank wall was shown in Fig. 12, the pressure data below and at the still water are chosen respectively. It can be seen that the main peak frequency component in the pressure history curve is the resonance frequency and its multiples, and the number of peaks in the LNG tanks was significantly fewer. The fewer peak frequencies in the spectrum curve mean less monochromatic wave components, indicating the weakly wave-wave interaction. The nonlinearity of the wave can be, in general, reflected by the asymmetry of the wave pattern. Fig. 13 shows the time history curve of the impact pressure on the side wall, and the pressure double peak phenomenon is obviously observed. From the view of the symmetry of the wave pattern, it concluded that the impact pressure at the still water level has a more typical nonlinear phenomenon, namely the pressure wave with flatter trough and sharper crest appears easily. Moreover, it is also observed in the spectrum curve that the amplitude of the second peak frequency relative to the first peak frequency is larger at the still water level, indicating the strongly wave-wave interaction. However, there is a strong nonlinear effect on the curved side wall of the spherical tank even below the free surface. 


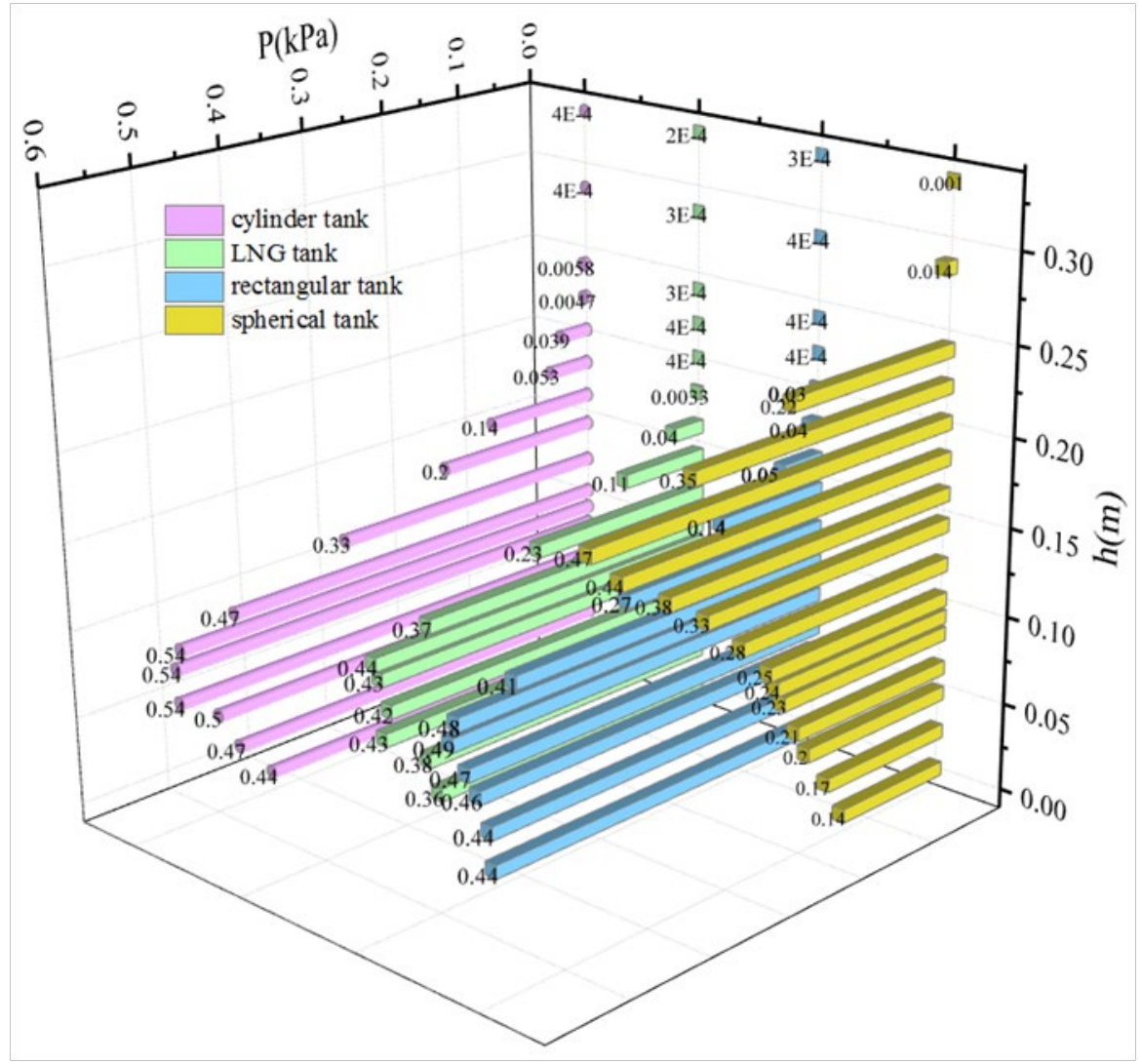

Fig. 10. Pressure distribution on side walls of four storage vessels of different shapes.

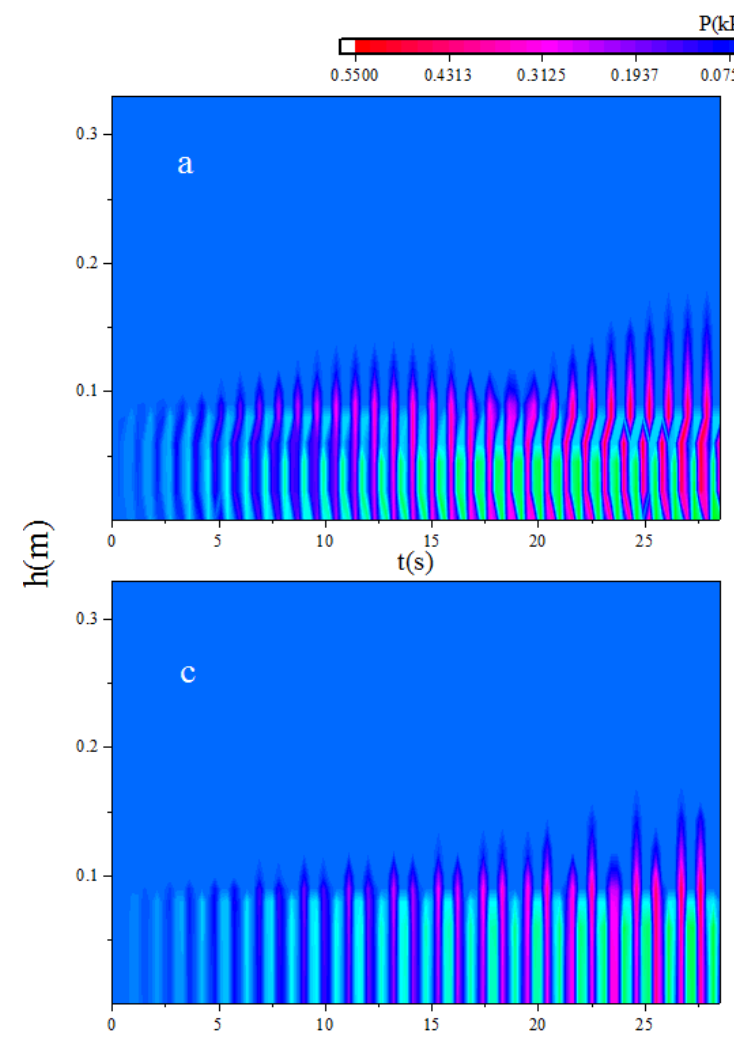

$\mathrm{t}(\mathrm{s})$
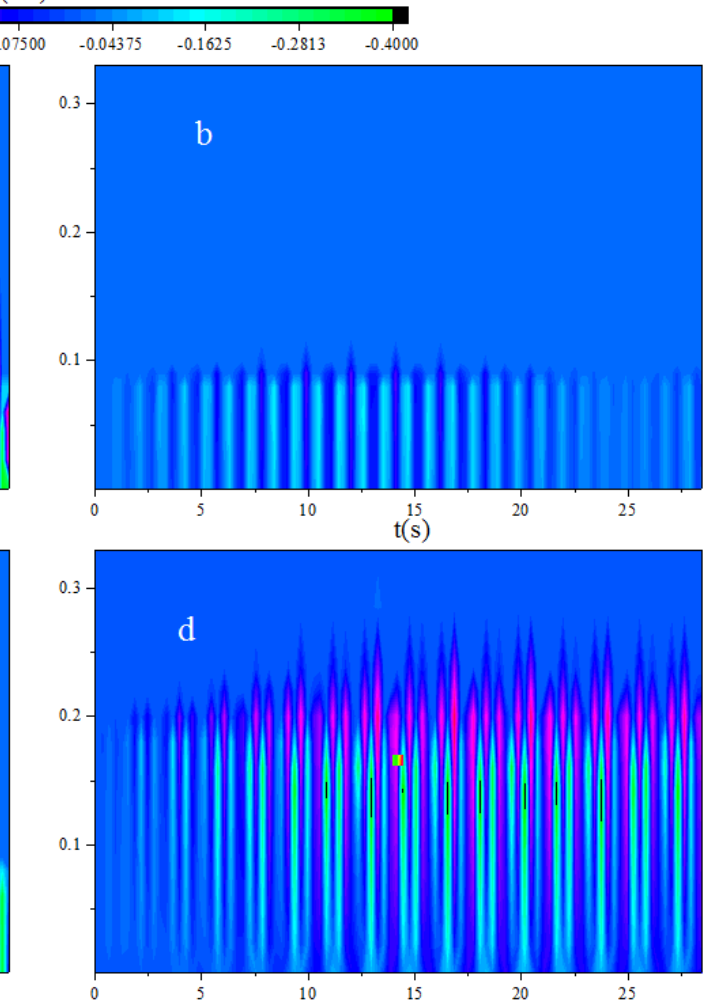

$\mathrm{t}(\mathrm{s})$

Fig. 11. History of the impact pressure on the side wall (a. cylindrical tank, b. LNG 
tank, c. rectangular tank, d. spherical tank.).
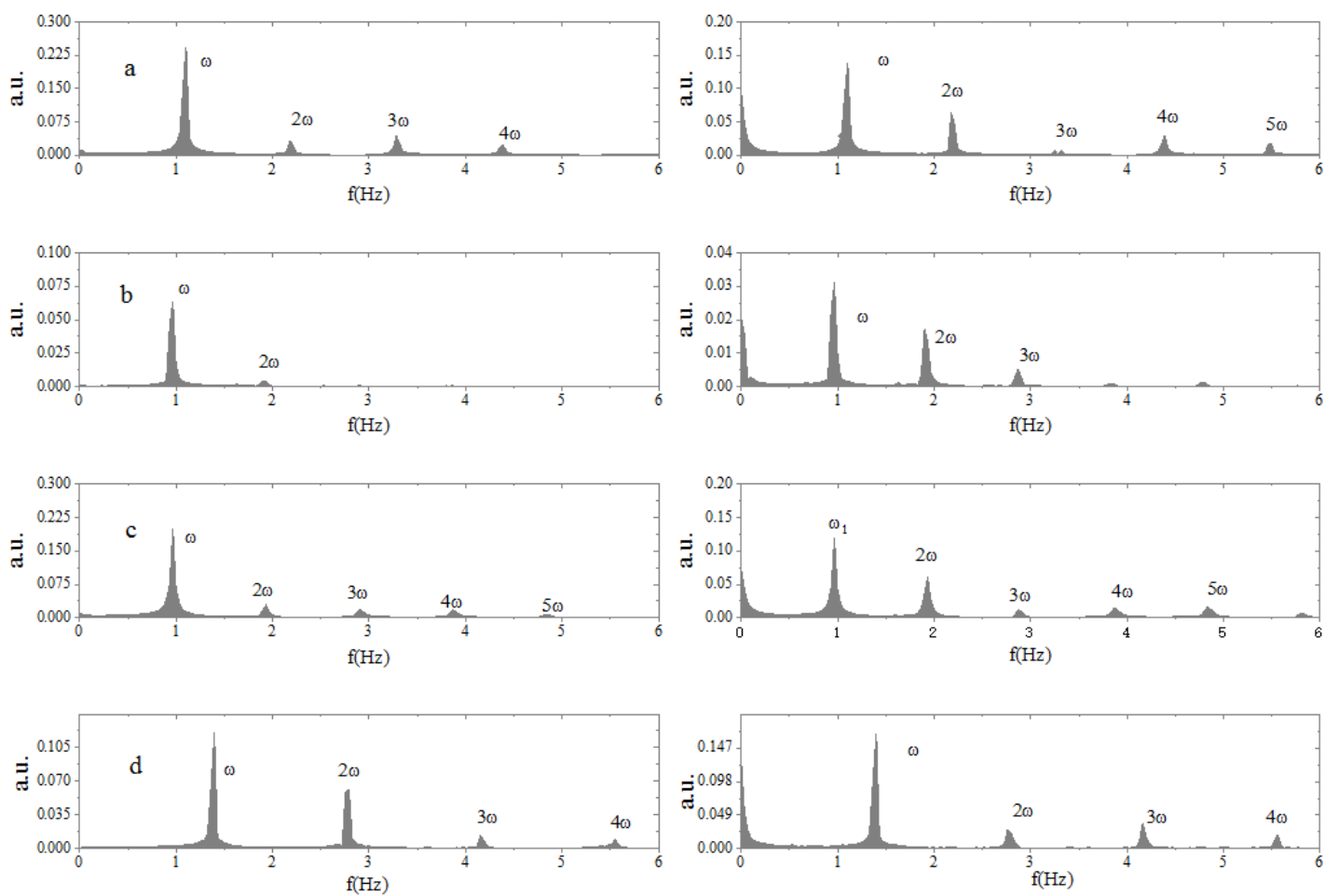

Fig. 12. FFT of impact pressure on the side wall (a. cylindrical tank, b. LNG tank, c. rectangular tank, d. spherical tank. left column: $h_{\text {probe }}=0.045 \mathrm{~m}$, right column:

$$
h_{\text {probe }}=\text { still water level }=0.09 \mathrm{~m} \text { ) }
$$



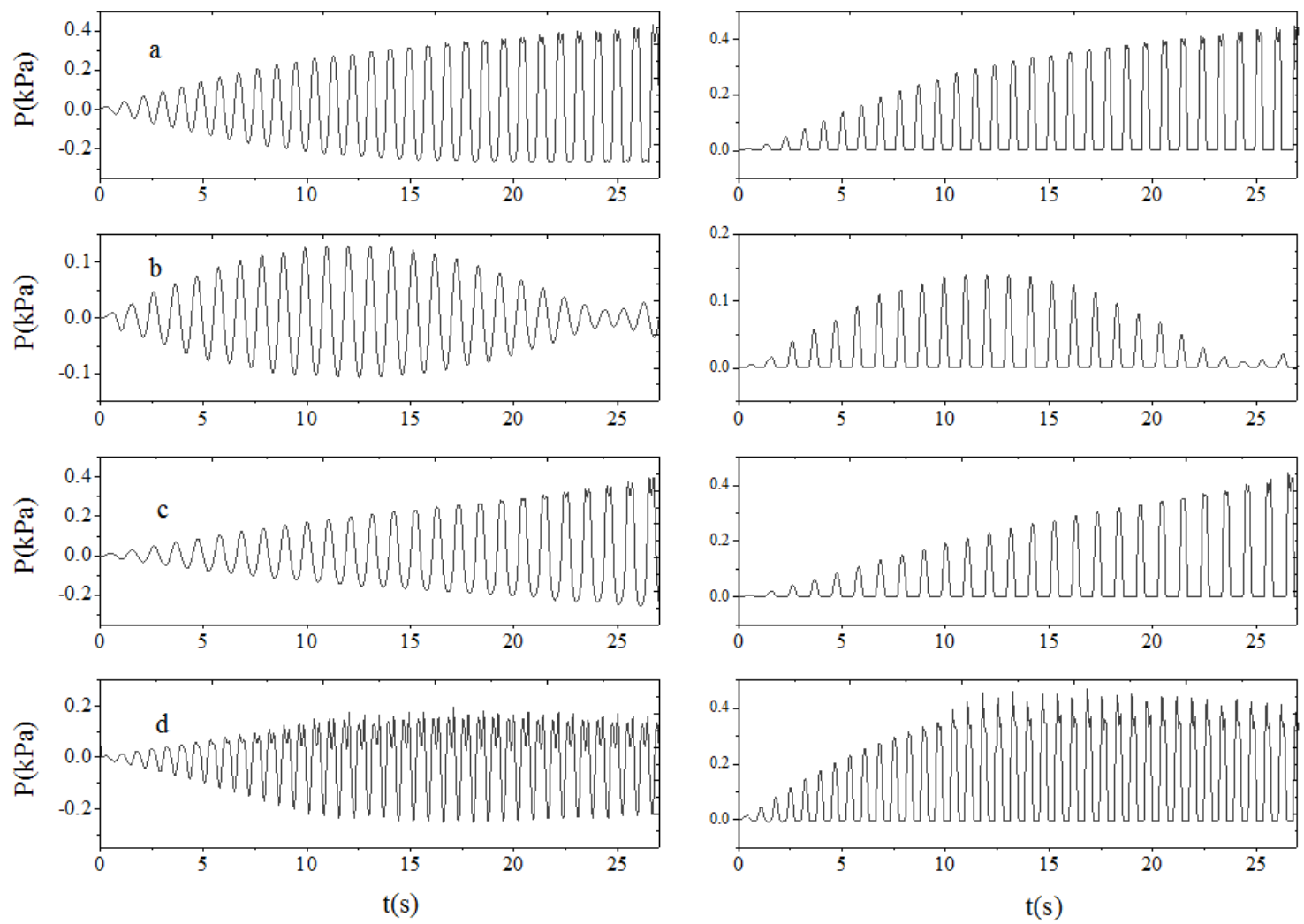

Fig. 13. Time history curve of impact pressure on the side wall (a. cylindrical tank,

b. LNG tank, c. rectangular tank, d. spherical tank. left column: $h_{\text {probe }}=0.045 \mathrm{~m}$, right column: $h_{\text {probe }}=$ still water level $=0.09 \mathrm{~m}$ ) 

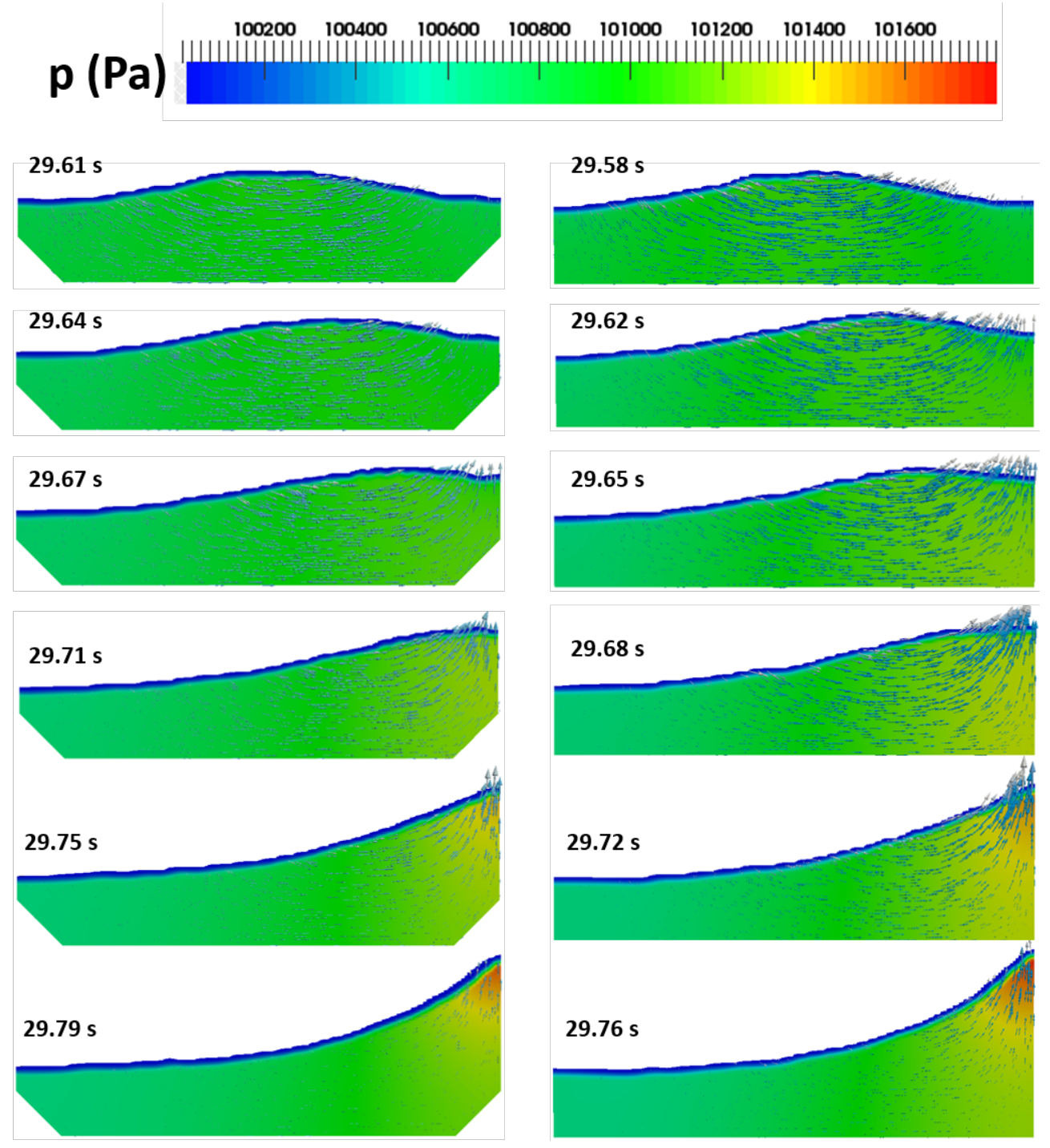

Fig. 14. Pressure distribution in liquid tanks during sloshing (The left column: the LNG tank, the right column: the rectangular tank).

Fig. 14 shows the pressure distribution and the velocity vector in the LNG and rectangular tanks under the resonance frequency. Snapshots at six moments during the most severe impact cycle are depicted and as the amplitude of the sloshing waves is relatively small, no wave breaking takes place. When the sloshing waves move from the middle of the tank to the side wall, it can be clearly seen that the pressure at the tank wall increases first, and then reaches a maximum value at the top of the wave as the liquid climbs up the wall. Under the same amplitude and resonance frequency, the reason why the LNG liquid tank has the lower impact pressure is that the slope at the tank bottom changes the flow direction, which reduces the impact speed at the side wall. 


\subsubsection{Three dimensional characteristics of sloshing in cylindrical and spherical tanks}

\section{a. Cylindrical tank}

In the above discussion, it was found the impact pressure in the cylindrical tank is larger than that in the other three tanks. To reveal the underlying sloshing dynamics for this, the pressure and the free surface elevation at various positions of the cylindrical tank under the single degree of freedom horizontal excitation are further examined. Fig. 15 shows the time history of the pressure and the free surface elevations at the center of the tank and 5 positions on the tank surface under the resonance excitation, the angle is measured from the horizontal line to the line connecting the measuring point and the center of the tank, the arrow indicates the direction of tank motion and the pressure data were taken from $0.045 \mathrm{~m}$ above the tank bottom. It is clearly shown that the closer to the point on the wall, which is directly opposite to the motion direction, the larger the impact pressures it will be subjected to. If the pressure at the point on the wall with a $0^{\circ}$ angle is taken as a reference, it will reduce to about $80 \%$ in the direction of $30^{\circ}, 60 \%$ in the direction of $45^{\circ}$, and $40 \%$ in the direction of $60^{\circ}$. In the $90^{\circ}$ direction, the pressure and the free surface elevation are very small in the first fifteen seconds, and increase gradually after that, presumably due to the reflected waves from the curved tank wall.

In order to investigate the $3 \mathrm{D}$ characteristics of the cylindrical tank and its influence on impact pressure, the impact process at an early stage without wave breaking and fully developed stage with wave breaking are shown in Fig. 16 respectively. Before wave breaking taking place, the tank was subjected to increasing impact pressure as the sloshing wave climbs, and an arch-shaped impact zone was formed around the free surface. After the wave breaking, the elevated wave front will fall onto the free surface causing small waves to spread along the side wall, which along with the returning waves lead to the wave impact pressure in the $90^{\circ}$ direction. These small waves merged with the main wave and impacted the other side. To investigate violent sloshing in the cylindrical tank, the resonance cases with amplitude of $0.007 \mathrm{~m}$ were studied. The time history of the pressure and the free surface elevations at different positions are shown in Fig. 17. Unlike the case with a small amplitude excitation, the impact pressure at the $30^{\circ}$ position is almost the same as the $0^{\circ}$ position after $5 \mathrm{~s}$, and the impact pressure amplitude at all the measured positions 
is similar after $20 \mathrm{~s}$. From the free surface contours shown in Fig. 18, when the wave breaks up violently with roof impact phenomenon and aeration taking place, the impact direction of the sloshing wave will shift away from the external excitation direction. After one period of flow development, a quasi-steady state of the sloshing wave rotates along the side wall has been reached and consequently the free surface elevation at the center decreases and the free surface elevation near the side wall increases.
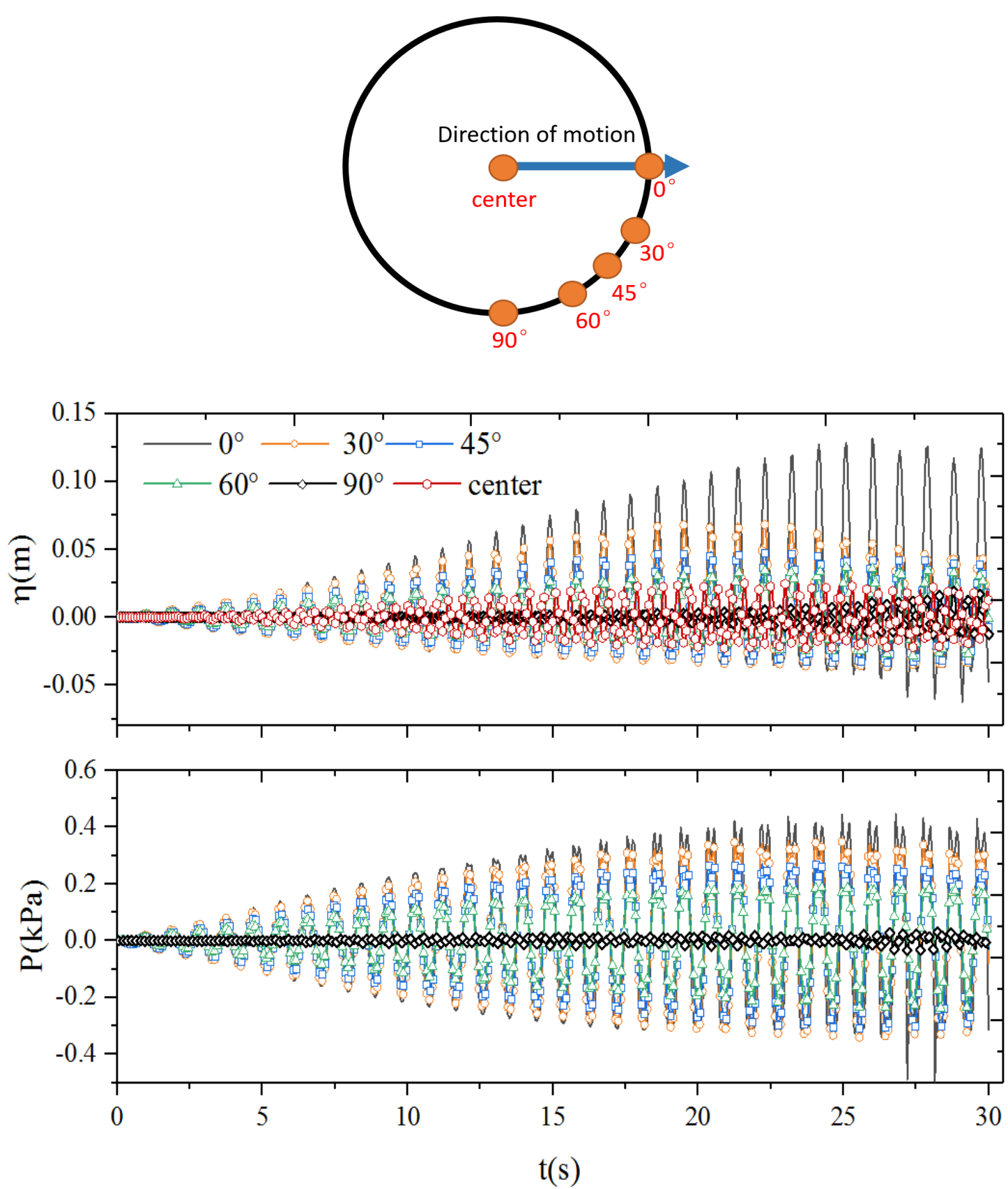

Fig. 15. Pressure and free surface elevation at different positions in the cylindrical $\operatorname{tank}\left(A=0.001 \mathrm{~m}, \omega=\omega_{1}\right)$. 


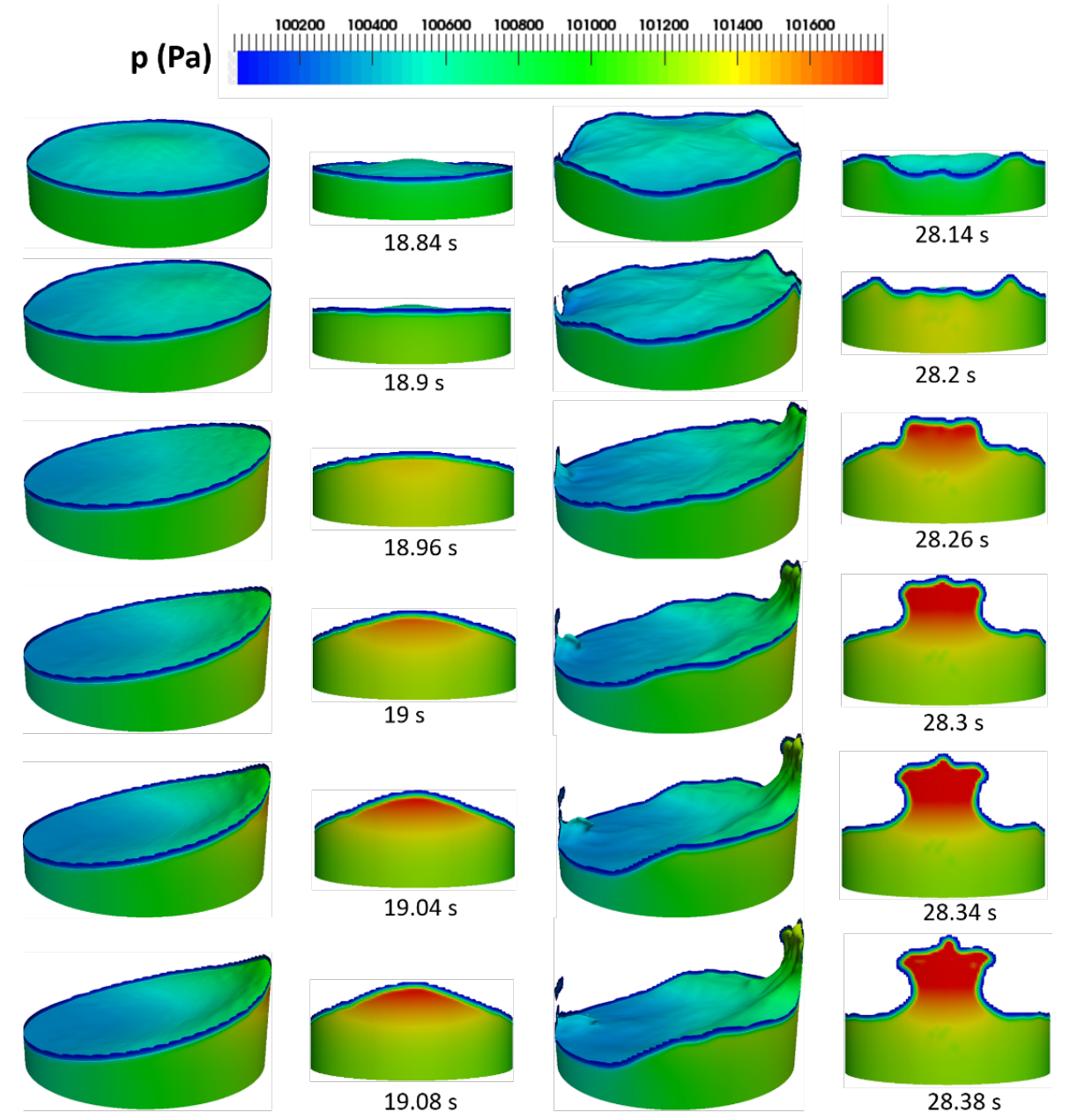

Fig. 16. The free surface and the pressure distribution in the cylindrical tank. 

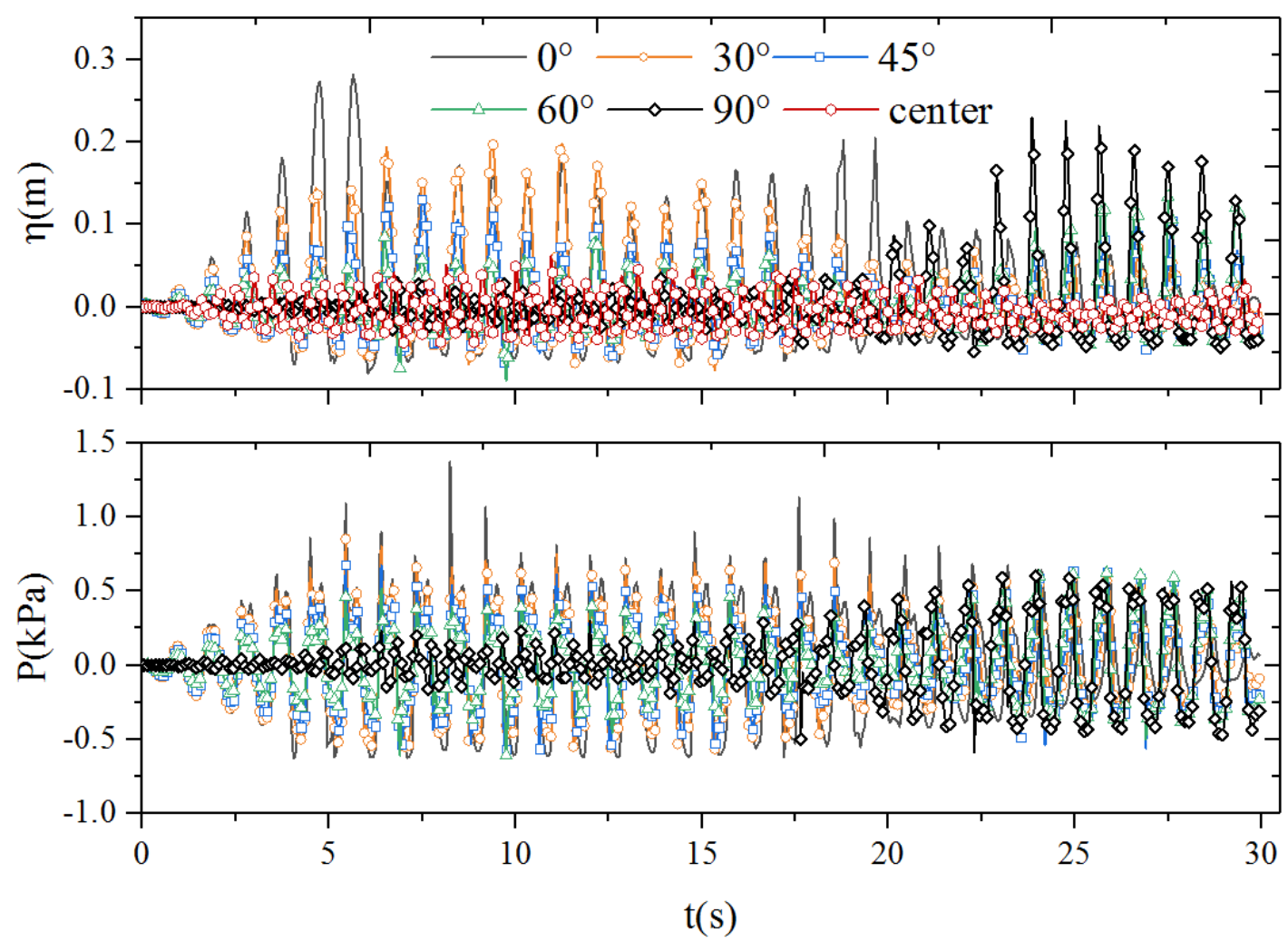

Fig. 17. The pressure and the free surface elevation at various positions in the cylindrical tank $\left(A=0.007 \mathrm{~m}, \omega=\omega_{1}\right)$.

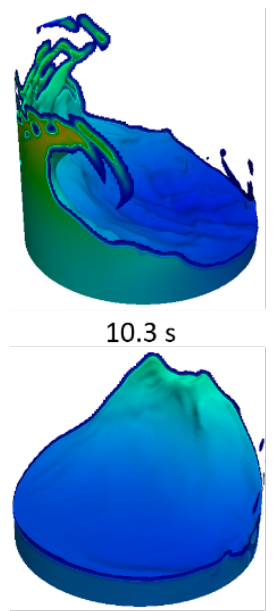

$26.56 \mathrm{~s}$

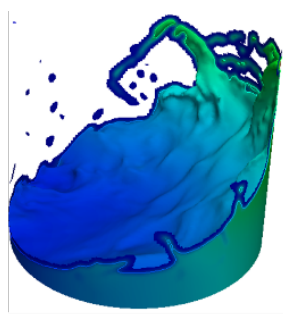

$17.36 \mathrm{~s}$

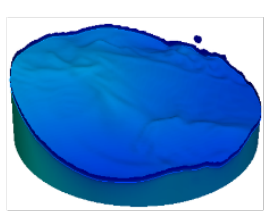

$27.76 \mathrm{~s}$

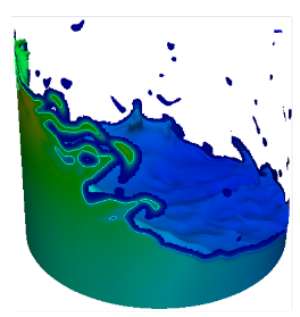

$19.7 \mathrm{~s}$

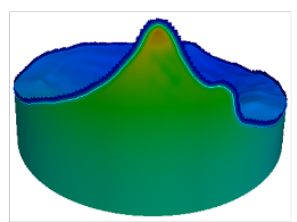

$27.96 \mathrm{~s}$

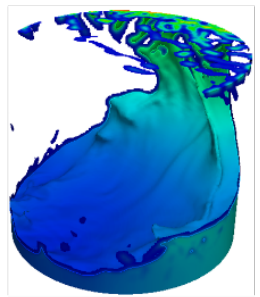

$21.12 \mathrm{~s}$

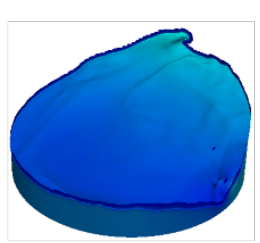

$28.26 \mathrm{~s}$

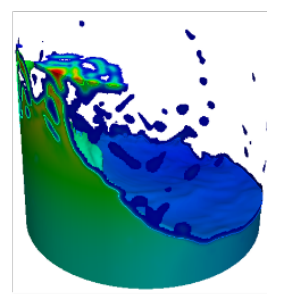

$22.4 \mathrm{~s}$

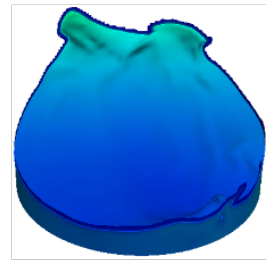

$28.4 \mathrm{~s}$

Fig. 18 The free surface of large amplitude resonance sloshing in the cylindrical tank.

\section{b. Spherical tank}

The impact pressure distributions and characteristics at different heights in the spherical tank are investigated in this section. Fig. 19 shows the pressure histories and 
its FFT signal in the frequency domain at different locations, and the positions of the pressure measurement points. As the position of the monitoring point moves up, the pressure amplitude gradually increases. If the pressure in the direction of $0^{\circ}$ is taken as a reference, it will reduce to about $60 \%$ in the direction of $30^{\circ}, 45 \%$ in the direction of $45^{\circ}, 35 \%$ in the direction of $60^{\circ}$, and $30 \%$ in the direction of $90^{\circ}$. At the $30^{\circ}$ position, the pressure measurement point is near the free surface, where the sloshing wave is easily breaking and then involves in a large number of air bubbles (Tai et al. 2019), thus forming a negative pressure cavity. The minimum pressure at the $30^{\circ}$ position is therefore significantly smaller than the others. The results of frequency domain analysis show that the main frequency component is the resonant frequency and its multiples; the pressure near the free surface has strong nonlinearity due to severe slamming. As the position of the monitoring point moves down, the energy at other peaks gradually decreases, leaving only the frequency component $2 \omega$, the reason may be the spherical sidewall changing the direction of the liquid impact and causing wave-wave nonlinear interaction.
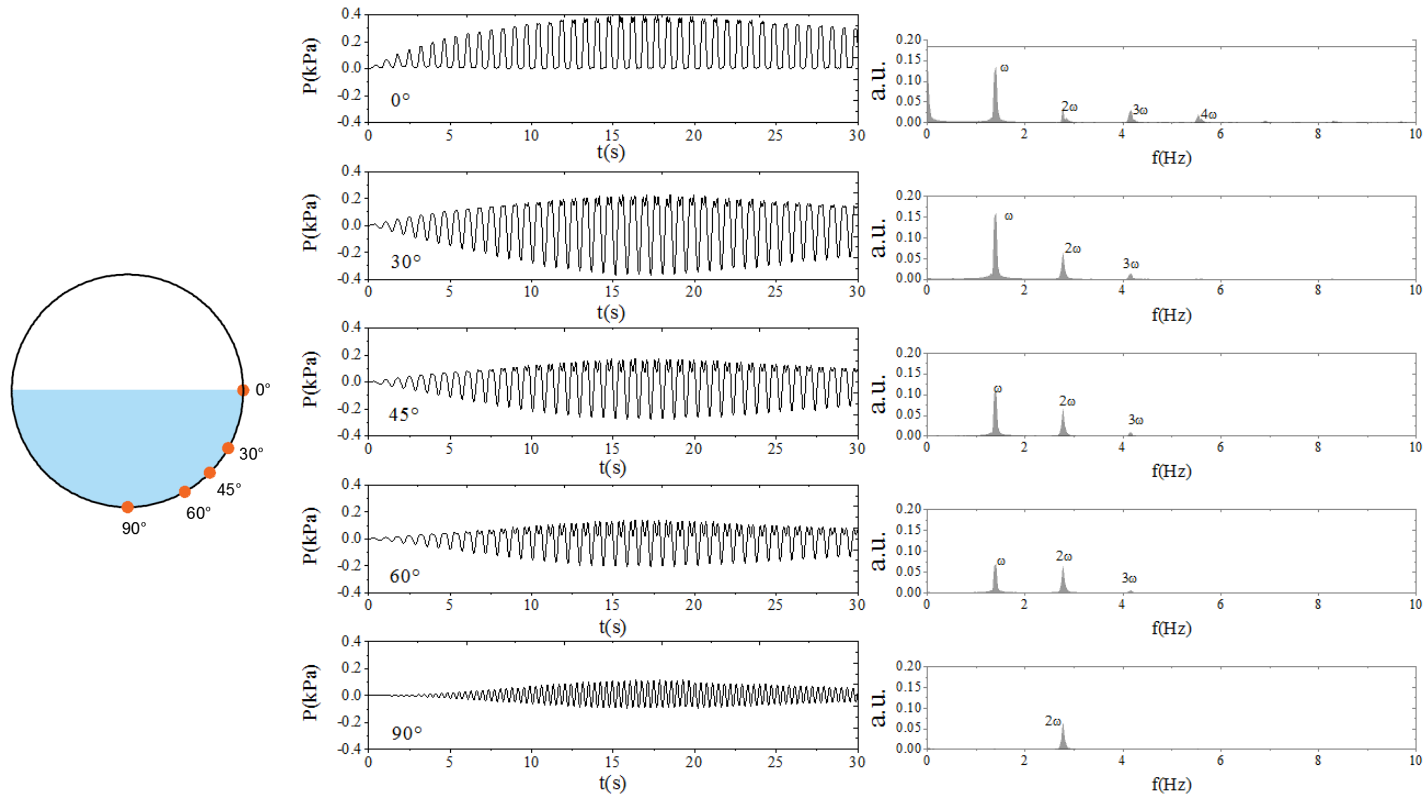

Fig. 19. Pressure at different positions in the spherical tank $\left(A=0.001 \mathrm{~m}, \omega=1.07 \omega_{1}\right)$.

Fig. 20 shows the free surface of the liquid inside the spherical tank in large amplitude with $0.007 \mathrm{~m}$ at resonant frequency of $1.07 \omega_{1}$ and small amplitude with $0.001 \mathrm{~m}$ at resonant frequency of $1.07 \omega_{1}$, respectively. Under the small amplitude and resonant conditions, the sloshing waves exhibit a form of standing wave with a slight 
breakage of the liquid edge. In the large amplitude case, the liquid surface breaks up more quickly and severely, and it can be clearly seen that a large amount of liquid rolls up along the sidewall of the sphere and then falls into the other end of the spherical tank, which causes liquid splashing and air entrainment.

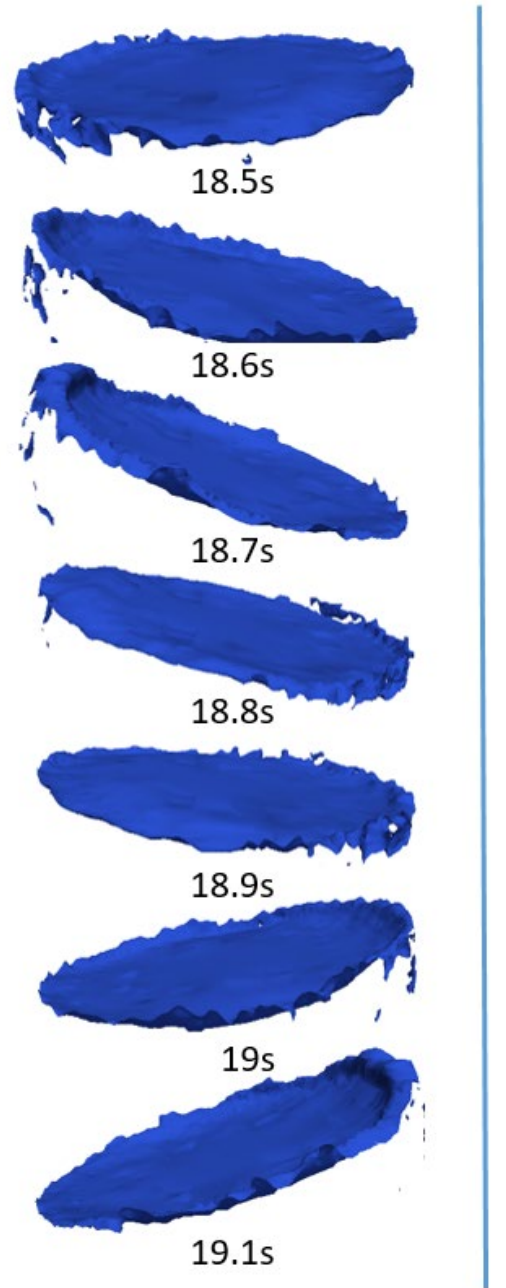

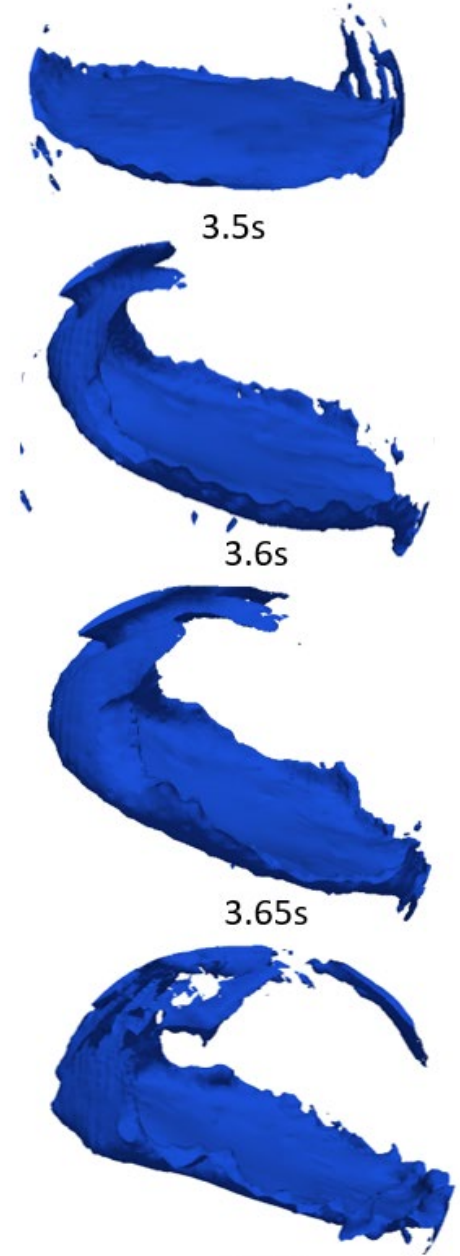

$3.75 \mathrm{~s}$

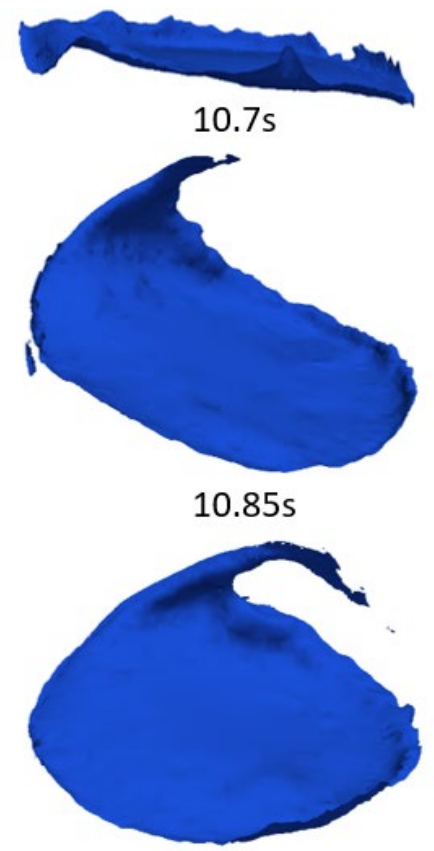

$10.95 s$

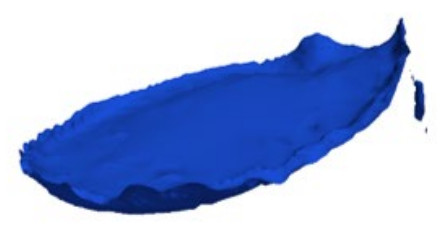

$11.1 \mathrm{~s}$

Fig. 20. The free surface in the spherical tank (The left column: $A=0.001 \mathrm{~m}$, and $\omega=1.07 \omega_{1}$; the right column: $A=0.007 \mathrm{~m}$, and $\left.\omega=1.07 \omega_{1}\right)$.

\section{Conclusions}

The suitability and accuracy of the OpenFOAM for solving sloshing problem were demonstrated through benchmark tests obtained from the available literatures. Effects of the storage vessel shapes on sloshing dynamics were investigated numerically. Largest impact pressures were found in the cylindrical tank, and the impact pressures in LNG tank are significantly lower than the other three tanks when considering the same volume of liquid. The resonant hysteresis happened in the LNG 
tank, the rectangular tank with low filling level and the spherical tank, but it did not occur in the cylindrical tank.

The maximum impact pressure on the tank wall first increases with the height and reaches the maximum value at around the still water level. The maximum impact pressures on the side wall below the still water level increases with the height but they drop quickly above the still water level. For the storage vessels with vertical sidewalls, the difference between the pressure at the bottom and the pressure at the still water level is less than $20 \%$. However, for the pressure distribution in the spherical tank, the impact pressure at the still water level is about three times that at the bottom with practical implications for the tank design.

From the time-continuous view of the computed pressure distribution on the side wall, it shows that the large impact pressure illustrated by the red area is local in both space and time. In terms of the size of the large impact area, the largest is the cylindrical tank, followed by the spherical tank and the rectangular tank, and the smallest is LNG tank. Besides, the region at the still water level is subjected to the impact for a longer time except for the cylindrical tank. The FFT analysis of pressure histories shows that the sloshing in the LNG tank has the weakest nonlinearity. With the same amplitude and resonance frequency, the reason why the LNG liquid tank endured the smallest impact pressure is that the slope at the tank bottom changes the direction of impact of the fluid reducing the velocity of the sloshing liquid.

For the sloshing in the cylindrical and spherical tanks with a horizontal excitation, strong 3D effects can be observed with violent wave breaking and aeration taking place and the maximum impact point shifting around the surface of the tank in the circumferential direction. Similar to the LNG tank, the curved surface of the spherical tank could also explain why the maximum impact pressure on it is lower than that of the cylindrical tank.

\section{Acknowledgments}

This work is supported by the National Natural Science Foundation of China (No. 51679079), the Fundamental Research Funds for the Central Universities (Nos. 2018B12814, 2019B61014, and 2019B19314), and the Postgraduate Research \& Practice Innovation Program of Jiangsu Province (No. SJKY19_0528). 


\section{References}

Abramson, H.N., Bass, R.L., Faltinsen, O., Olsen, H.A., 1976. Liquid slosh in LNG carriers. Symposium on Naval Hydrodynamics, $10^{\text {th }}$, Proceedings, Pap and Discuss, Cambridge, Mass, June 24-28, 371-388.

Akyildiz, H., Ünal, N.E., 2005. Experimental investigation of pressure distribution on a rectangular tank due to the liquid sloshing. Ocean Eng. 32(11), 1503-1516.

Akyildiz, H., Ünal, N.E., Aksoy, H., 2013. An experimental investigation of the effects of the ring baffles on liquid sloshing in a rigid cylindrical tank. Ocean Eng. 59(1), 190-197.

Arai, M., 1984. Experimental and numerical studies of sloshing pressure in liquid cargo tanks. Journal of the Japan Society of Naval Architects \& Ocean Engineers. $155,114-121$.

Chen,Y.H., Hwang, W.S., Ko, C.H., 2007. Sloshing behaviours of rectangular and cylindrical liquid tanks subjected to harmonic and seismic excitations. Earthq. Eng. Struct. Dyn. 36, 1701-1717.

Chen, Y.C., Xue, M.-A., 2018. Numerical simulation of liquid sloshing with different filling levels using OpenFOAM and experimental validation. Water, 10(12), 1-18.

Chiba, M., Abe, K., 1999. Nonlinear hydroelastic vibration of a cylindrical tank with an elastic bottom containing liquid-analysis using harmonic balance method. Thin Wall Struct. 34(3), 233-260.

Chiba, M., Murase, R., Kimura, R., Yamamoto, Y., Komatsu, K., 2016. Experimental studies on the dynamic stability of liquid in a spherical tank covered with diaphragm under vertical excitation. J. Fluid Struct. 61, 218-248.

Dragomir, S.C., Sinnott, M., Semercigil, E.S., Turan, O.F., 2012. Energy dissipation characteristics of particle sloshing in a rotating cylinder. J. Sound Vibr. 331(5), 963-973.

Faltinsen, O.M., 1974. A nonlinear theory of sloshing in rectangular tanks. J. Ship Res. 18(4), 224-241.

Faltinsen, O.M., Rognebakke, O.F., Lukovsky, I.A., Timokha, A.N., 2000. Multidimensional modle analysis of nonlinear sloshing in a rectangular tank with finite water depth. J. Fluid Mech. 407, 201-234.

Faltinsen, O.M., Timokha, A.N., 2001. An adaptive multimodel approach to nonlinear sloshing in a rectangular tank. J. Fluid Mech. 432, 167-200.

Faltinsen, O.M., Timokha, A.N., 2009. Sloshing. Cambridge University Press: 
Cambridge, UK.

Graczyk, M., Moan, T., 2008. A probabilistic assessment of design sloshing pressure time histories in LNG tanks. Ocean Eng. 35(8), 834-855.

Karamanos, S.A., Patkas, L.A., Platyrrachos, M.A., 2006. Sloshing effects on the seismic design of horizontal-cylindrical and spherical industrial vessels. J. Press. Vess. T. ASME. 128, 328-340.

Koh, C.G., Luo, M., Gao, M., Bai, W., 2013. Modelling of liquid sloshing with constrained floating baffle. Comput. Struct. 22, 270-279.

Lee, S.J., Kim, M.H., Lee, D.H., Kim, J.W., Kim, Y.H., 2007a. The effects of LNG-tank sloshing on the global motions of LNG carriers. Ocean Eng. 34(1), $10-20$.

Lee, D.H., Kim, M.H., Kwon, S.H., Kim, J.W., Lee, Y.B., 2007b. A parametric sensitivity study on LNG tank sloshing loads by numerical simulations. Ocean Eng. 34(1), 3-9.

Liu, D.M., Lin, P.Z., 2008. A numerical study of three-dimensional liquid sloshing in tanks. J. Comput. Phys. 227(8), 3921-3939.

Luo, M., Koh, C.G., Bai, W., 2016. A three-dimensional particle method for violent sloshing under regular and irregular excitations. Ocean Eng. 120:52-63.

Luo, M., Koh, C.G., 2017. Shared-Memory parallelization of consistent particle method for violent wave impact problems. Appl. Ocean Res. 69:87-99.

Maleki, A., Ziyaeifar, M., 2008. Sloshing damping in cylindrical liquid storage tanks with baffles. J. Sound Vibr. 311(1), 372-385.

Mciver, P., 1989. Sloshing frequencies for cylindrical and spherical containers filled to an arbitrary depth. J. Fluid Mech. 201, 243-257.

Rawat, A., Mittal, V., Chakraborty, T., et al., 2019. Earthquake induced sloshing and hydrodynamic pressures in rigid liquid storage tanks analyzed by coupled acoustic-structural and Euler-Lagrange methods. Thin Wall Struct. 134, 333-346.

Tai, B., Ma, Y.X., Niu, X.Y., Dong, G.H., Perlin, M., 2019. Experimental investigation of impact forces induced by plunging breakers on a vertical cylinder. Ocean Eng. $189,106362$.

Van Twillert, M.J., 2015. The effect of sloshing in partially filled spherical LNG tanks on ship motions. MSC Thesis, Delft University of Technology, 1-127.

Virella, J.C., Prato, C.A., Godoy, L.A., 2008. Linear and nonlinear 2D finite element analysis of sloshing modes and pressures in rectangular tanks subject to horizontal 
harmonic motions. J. Sound Vibr. 312(3), 442-460.

Wang, Z.L., Deng, Z.P., 1985. Sloshing of liquid in spherical tank at low-gravity environments. Chinese J. Space Sci. 5, 294-302.

Xue, M.-A., Lin, P.Z., 2011. Numerical study of ring baffle effects on reducing violent liquid sloshing. Comput. Fluids. 52, 116-129.

Xue, M.-A., Zheng, J.H., Lin, P., 2012. Numerical simulation of sloshing phenomena in cubic tank with multiple baffles. J. Appl. Math. 2012, 1-21.

Xue, M.-A., Lin, P., Zheng, J.H., Ma, Y., Yuan, X., Nguyen, V.T., 2013. Effects of perforated baffle on reducing sloshing in rectangular tank: experimental and numerical study. China Ocean Eng. 27, 615-628.

Xue, M.-A., Zheng, J.H., Lin, P.Z., Xiao, Z., 2017a. Violent transient sloshing-wave interaction with a baffle in a three-dimensional numerical tank. J. Ocean Univ. China. 16, 661- 673.

Xue, M.-A., Zheng, J.H., Lin, P.Z., Yuan, X.L., 2017b. Experimental study on vertical baffles of different configurations in suppressing sloshing pressure. Ocean Eng. $136,178-189$.

Ye, L.U., Bei, T., En-Rong, Q.I., Chen, X.P., 2012. Structural Dynamic Response Study of Large LNG Carriers under Sloshing Impacts in Tanks. J. Ship Res. 85(12), 967-973.

Zhang, W., Cao, Y., Zhu, Y., Zheng, J., Ji, X., Xu, Y., Wu, Y., Hoitink, A.J.F., 2018. Unravelling the causes of tidal asymmetry in deltas. J. Hydrol. 564, 588-604.

Zhao, Y., Chen, H.C., 2015. Numerical simulation of 3D sloshing flow in partially filled LNG tank using a coupled level-set and volume-of-fluid method. Ocean Eng. 104, 10-30.

Zhao, D.Y., Hu, Z.Q., Chen, G., Lim, S., Wang, S.Q., 2018a. Nonlinear sloshing in rectangular tanks under forced excitation. Int. J. Nav. Arch. Ocean Eng. 10, $545-565$.

Zhao, W., Taylor, P.H., Wolgamot, H.A., Taylor, R.E., 2018b. Identifying linear and nonlinear coupling between fluid sloshing in tanks, roll of a barge and external free-surface waves. J. Fluid Mech. 844, 403-434. 